\title{
FY16 Q3 Milestone Report for Geothermal Vision Study Thermal Application (Geothermal Heat Pump) Complete Simulations of GHP Installations for Representative Buildings
}

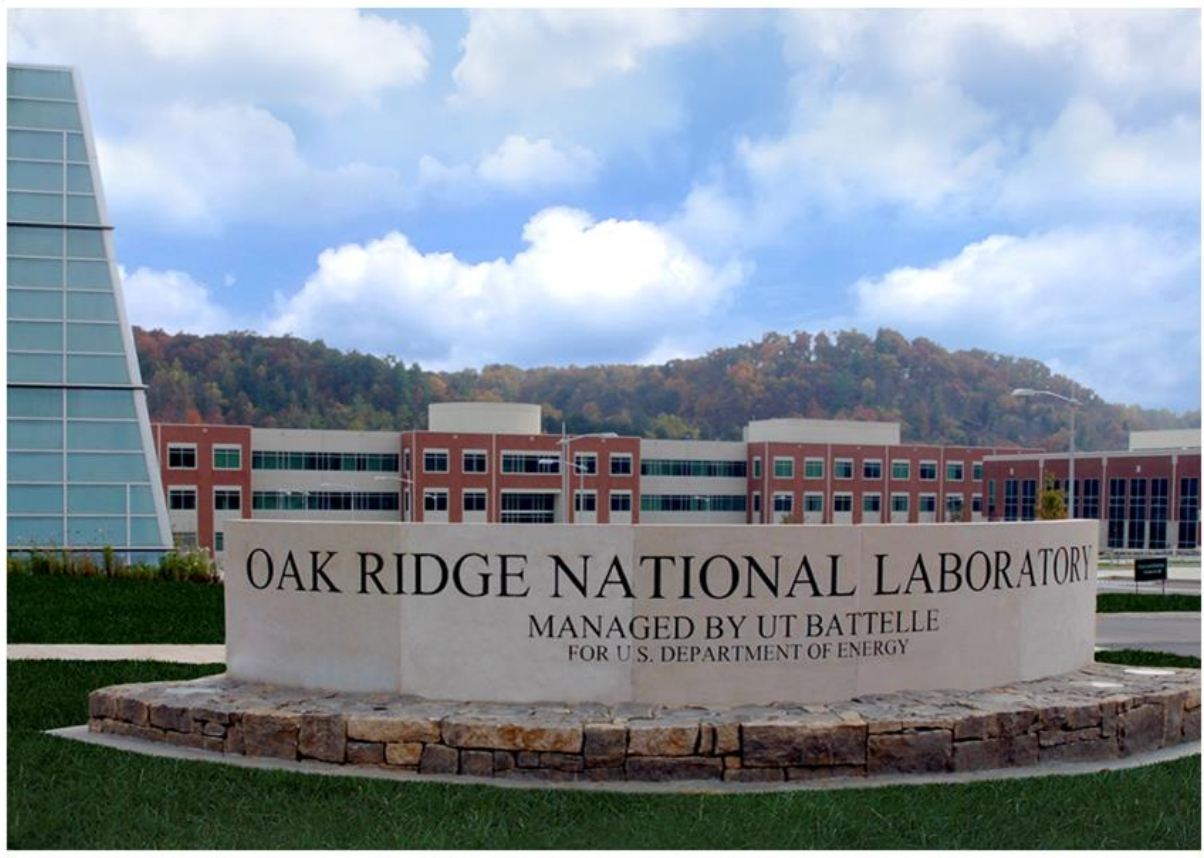

Approved for public release. Distribution is unlimited.
Xiaobing Liu Joseph Warner Mark Adams

July 2016 


\section{DOCUMENT AVAILABILITY}

Reports produced after January 1, 1996, are generally available free via US Department of Energy (DOE) SciTech Connect.

Website http://www.osti.gov/scitech/

Reports produced before January 1,1996, may be purchased by members of the public from the following source:

National Technical Information Service

5285 Port Royal Road

Springfield, VA 22161

Telephone 703-605-6000 (1-800-553-6847)

TDD 703-487-4639

Fax 703-605-6900

E-mailinfo@ntis.gov

Website http://www.ntis.gov/help/ordermethods.aspx

Reports are available to DOE employees, DOE contractors, Energy Technology Data Exchange representatives, and International Nuclear Information System representatives from the following source:

Office of Scientific and Technical Information

PO Box 62

Oak Ridge, TN 37831

Telephone 865-576-8401

Fax 865-576-5728

E-mail reports@osti.gov

Website http://www.osti.gov/contact.html

This report was prepared as an account of work sponsored by an agency of the United States Government. Neither the United States Government nor any agency thereof, nor any of their employees, makes any warranty, express or implied, or assumes any legal liability or responsibility for the accuracy, completeness, or usefulness of any information, apparatus, product, or process disclosed, or represents that its use would not infringe privately owned rights. Reference herein to any specific commercial product, process, or service by trade name, trademark, manufacturer, or otherwise, does not necessarily constitute or imply its endorsement, recommendation, or favoring by the United States Government or any agency thereof. The views and opinions of authors expressed herein do not necessarily state or reflect those of the United States Government or any agency thereof. 
Energy and Transportation Science Division

\section{FY16 Q3 MILESTONE REPORT FOR GEOTHERMAL VISION STUDY THERMAL APPLICATION (GEOTHERMAL HEAT PUMP) COMPLETE SIMULATIONS OF GHP INSTALLATIONS FOR REPRESENTATIVE BUILDINGS}

Xiaobing Liu

Joseph Warner

Mark Adams

Date Published: July 2016

Prepared by

OAK RIDGE NATIONAL LABORATORY

Oak Ridge, TN 37831-6283

managed by

UT-BATTELLE, LLC

for the

US DEPARTMENT OF ENERGY

under contract DE-AC05-00OR22725 



\section{CONTENTS}

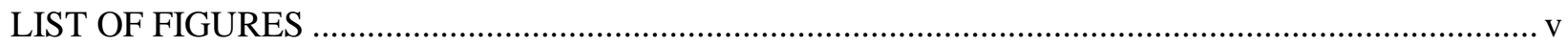

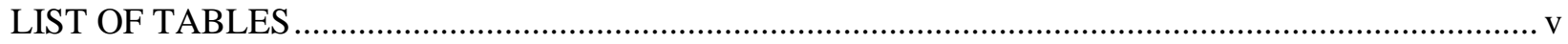

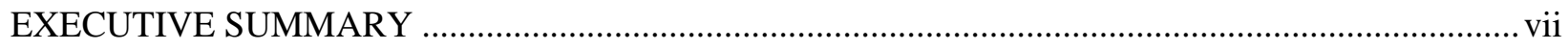

1. SIMULATIONS OF GHP SYSTEMS AT REPRESENTATIVE COMMERCIAL

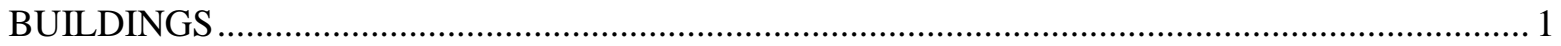

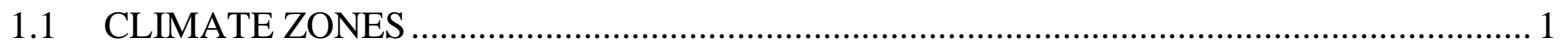

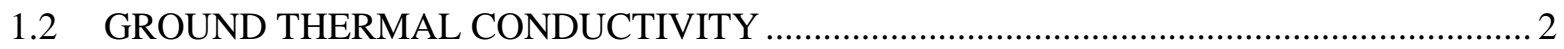

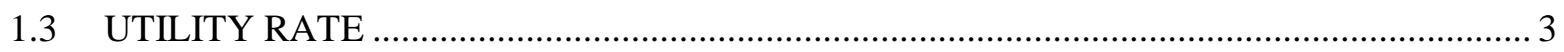

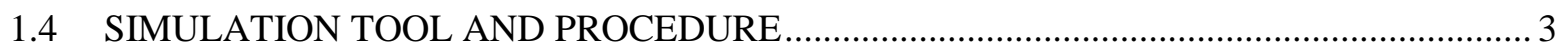

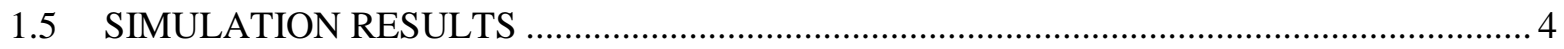

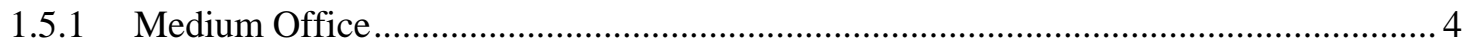

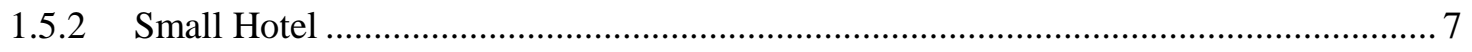

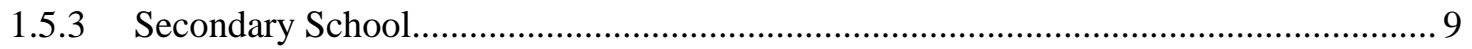

2. COST MODELS FOR GHP AND CONVENTIONAL HVAC SYSTEMS ................................... 11

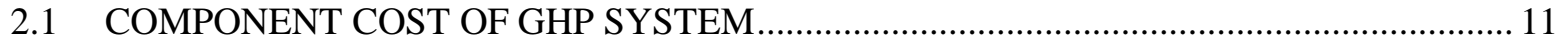

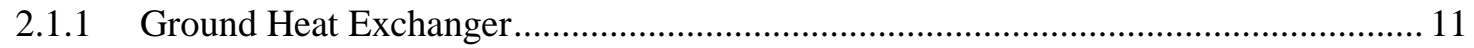

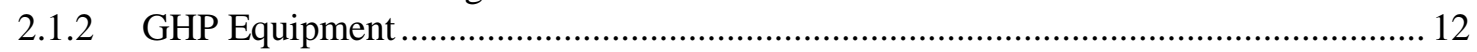

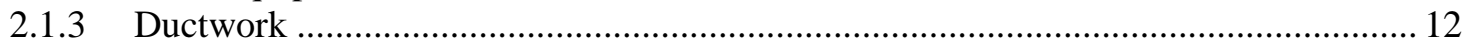

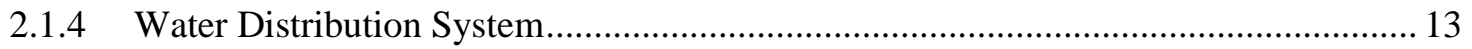

2.2 COMPONENT COST OF CONVENTIONAL HVAC SYSTEM ..................................... 13

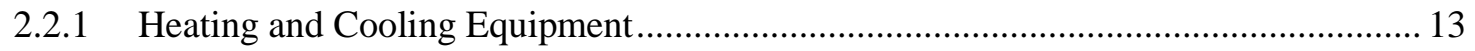

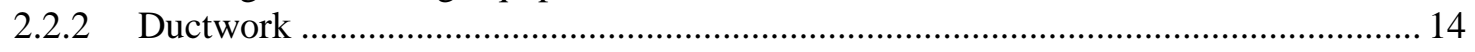

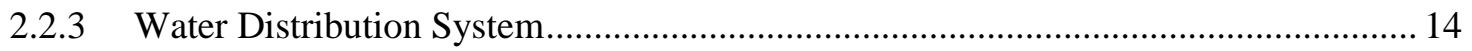

3. UPDATED TECHNICAL POTENTIAL FOR RESIDENTIAL GHP APPLICATIONS ................. 15

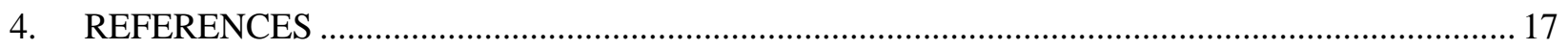





\section{LIST OF FIGURES}

Fig. ES-1. Annual electricity saving percentages by building types and locations. ............................... viii

Fig. ES-2. Annual natural gas saving percentages by building types and locations. ................................. viii

Fig. ES-3. Annual energy cost saving percentages by building types and locations................................. ix

Fig. ES-4. Annual source energy reduction percentages by building types and locations...........................

Fig. ES-5. Annual carbon emission reduction percentages by building types and locations......................

Fig. ES-6. Annual peak electricity demand reduction percentages by building types and locations........... xi

Fig. ES-7. Normalized ground heat exchanger sizes by building types and locations. .............................. xi

Fig. 1. Linear curve fit of available cost data of packaged VAV systems. ............................................... 4

Fig. 2. 3-D rendering of the modeled medium-sized office building.........................................................5

Fig. 3. Site energy saving percentages for the medium office by climate zone.........................................5

Fig. 4. Source energy, carbon emission, and energy cost reduction percentages for the medium office by climate zone.......................................................................................................... 6

Fig. 5. Peak electric demand reduction percentages for the medium office by climate zone...................... 6

Fig. 6. 3-D rendering of the modeled small hotel building. ............................................................... 7

Fig. 7. Site energy saving percentages for the small hotel by climate zone ......................................... 8

Fig. 8. Source energy, carbon emission, and energy cost reduction percentages for the small hotel

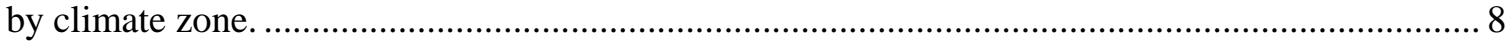

Fig. 9. Peak electric demand reduction percentages for the small hotel by climate zone.......................... 9

Fig. 10. 3-D rendering of the modeled secondary school building........................................................ 9

Fig. 11. Site energy saving percentages for the secondary school by climate zone................................. 10

Fig. 12. Source energy, carbon emission, and energy cost reduction percentages for the secondary

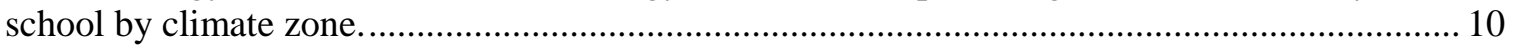

Fig. 13. Peak electric demand reduction percentages for the small hotel by climate zone....................... 11

Fig. 14. Polynomial curve fit of available cost data of packaged VAV systems. .................................... 13

Fig. 15. Linear curve fit of available cost data of packaged VAV systems............................................ 14

\section{LIST OF TABLES}

Table 1. Representative Cities of Selected Climate Zones ................................................................. 2

Table 2. Typical Values of Ground Thermal Conductivity in Selected States ........................................... 2

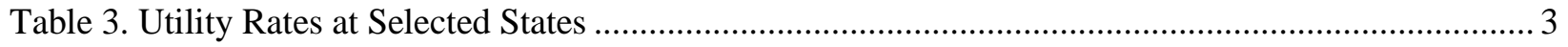

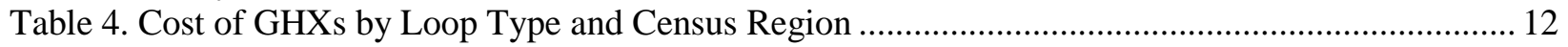

Table 5. Cost of Water Source Heat Pump by Cooling Capacity ........................................................... 12

Table 6. Cost of Multi-Zone Packaged VAV System by Cooling Capacity ........................................... 13

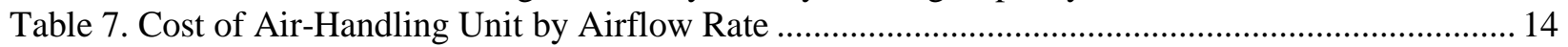

Table 8. Cost of Water-Cooled Electric Chiller by Capacity................................................................... 15

Table 9. Cost of Gas-Fired Hot Water Boiler by Capacity ….............................................................. 15

Table 10. Typical SH-SC-WH systems Used in US Single-Family Units ............................................. 16

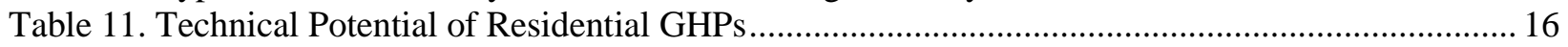





\section{EXECUTIVE SUMMARY}

This report summarizes the work for the Geothermal Vision Study for Thermal Applications (Geothermal Heat Pump) Q3 milestone of the FY16 project.

\section{Q3: Complete simulations of GHP installations for representative buildings}

- Performed computer simulations for the representatives of three types of buildings - medium-sized offices, small hotels, and secondary schools - in 13 different climate zones in the United States. These buildings are best fit for geothermal heat pump (GHP) applications given the significant energy consumption for space conditioning and the availability of land for ground heat exchanger (GHX) installation. The representative building models are adopted from the commercial reference buildings, which the Department of Energy (DOE) developed in conjunction with its national laboratories (NREL 2011). For each modeled building, simulations of both a distributed GHP system and a baseline HVAC system are conducted. For the GHP system simulations, three different ground thermal conductivity (TC) values, representing the $20^{\text {th }}, 50^{\text {th }}$, and $75^{\text {th }}$ quartiles of the TCs in each climate zone, are used to size the GHX of GHP systems.

- Calculated the site and source energy savings, carbon emission reductions, energy cost savings, and peak electricity demand reductions resulting from GHP applications in each simulated case.

- Created generic cost models for the GHP system and selected baseline HVAC systems based on the latest RSMeans cost data and other available literature. These cost models account for different system capacities for a given building at various climates. In addition, for GHP systems, the cost model also accounts for the size of GHXs, which is affected not only by the system capacity but also by the ground thermal properties at a given location (e.g., the undisturbed ground temperature and ground TC).

- Updated residential energy savings by using the updated efficiencies of existing residential baseline space cooling equipment.

Below is a summary of the simulation results. Figure ES-1 shows the changes in electricity consumption resulting from retrofitting the baseline HVAC system of each representative building at 13 different cities (each representing a climate zone). As demonstrated in the figure, changes in electricity consumptions develop two different patterns. For the medium office and small hotel, both of which use electric resistance heating (either as supplemental or primary heating) in their baseline HVAC systems, the GHP retrofits can reduce electricity consumption by 9 to $45 \%$. However, this tactic was not successful for medium offices in Phoenix, AZ and San Diego, CA, where there is little difference between the ambient air temperature and the supply water temperature from the GHX, and the electricity use increases by 3$4 \%$. Still, for the secondary school, which uses only natural gas for space heating, the GHP retrofits result in less than $18 \%$ reduction in electricity consumption at 10 of the 13 locations, and even increase electricity consumption by up to $14-17 \%$ in cold locations (e.g., Minneapolis, MN, and Helena, MT). The weather condition and baseline system design also affect the changes in electricity consumption. 


\section{Electricity Consumption Savings}

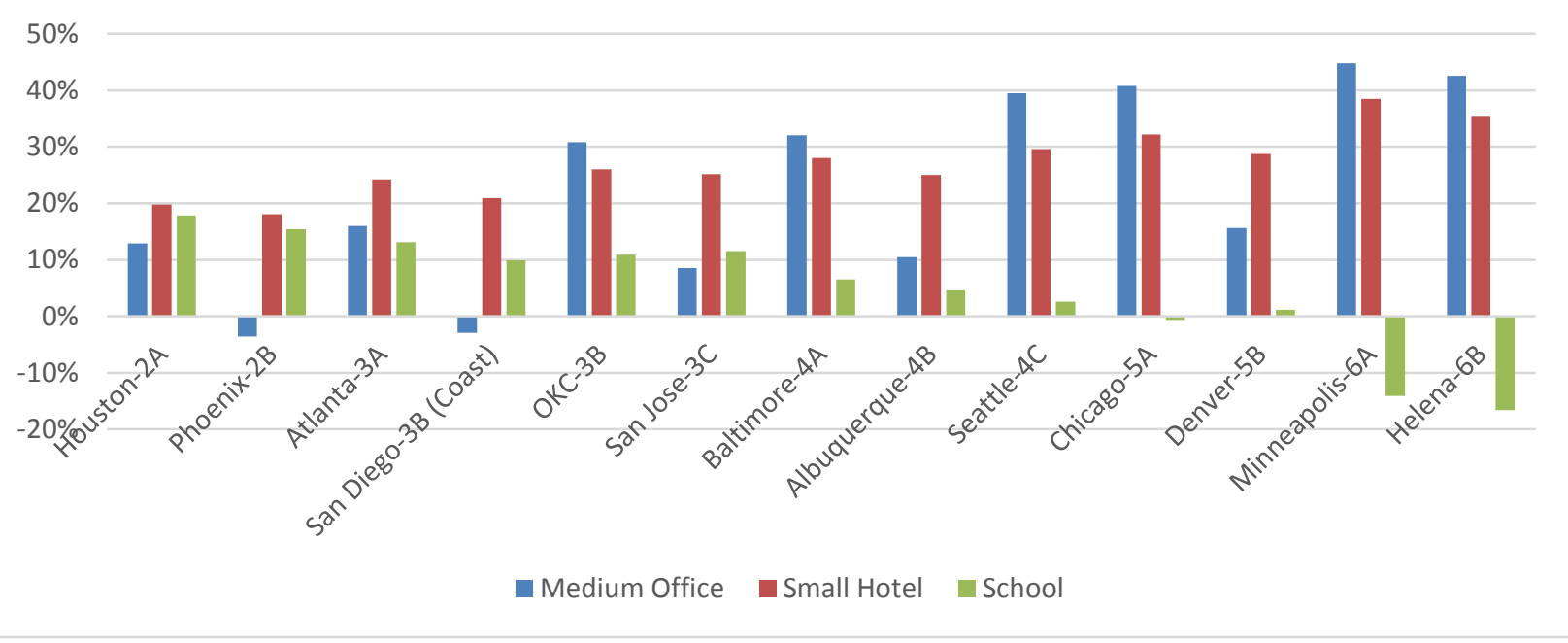

Fig. ES-1. Annual electricity saving percentages by building types and locations.

Figure ES-2 shows that the GHP retrofits completely eliminate the natural gas consumption at the medium office and the secondary school, where the entire baseline system is replaced with the GHP system. However, natural gas consumption is reduced only up to $67 \%$ at the small hotel, where a small portion of the baseline HVAC system (i.e., the makeup air system using a gas-fired furnace) was not replaced with the GHP system. The system was not replaced because of significant variation in outdoor air temperature, especially in locations with cold climates. Combining savings in electricity and natural gas consumptions, the average site energy saving percentages across all the climate zones are $27 \%$ at the modeled medium office, $26 \%$ at the small hotel, and $42 \%$ at the secondary school.

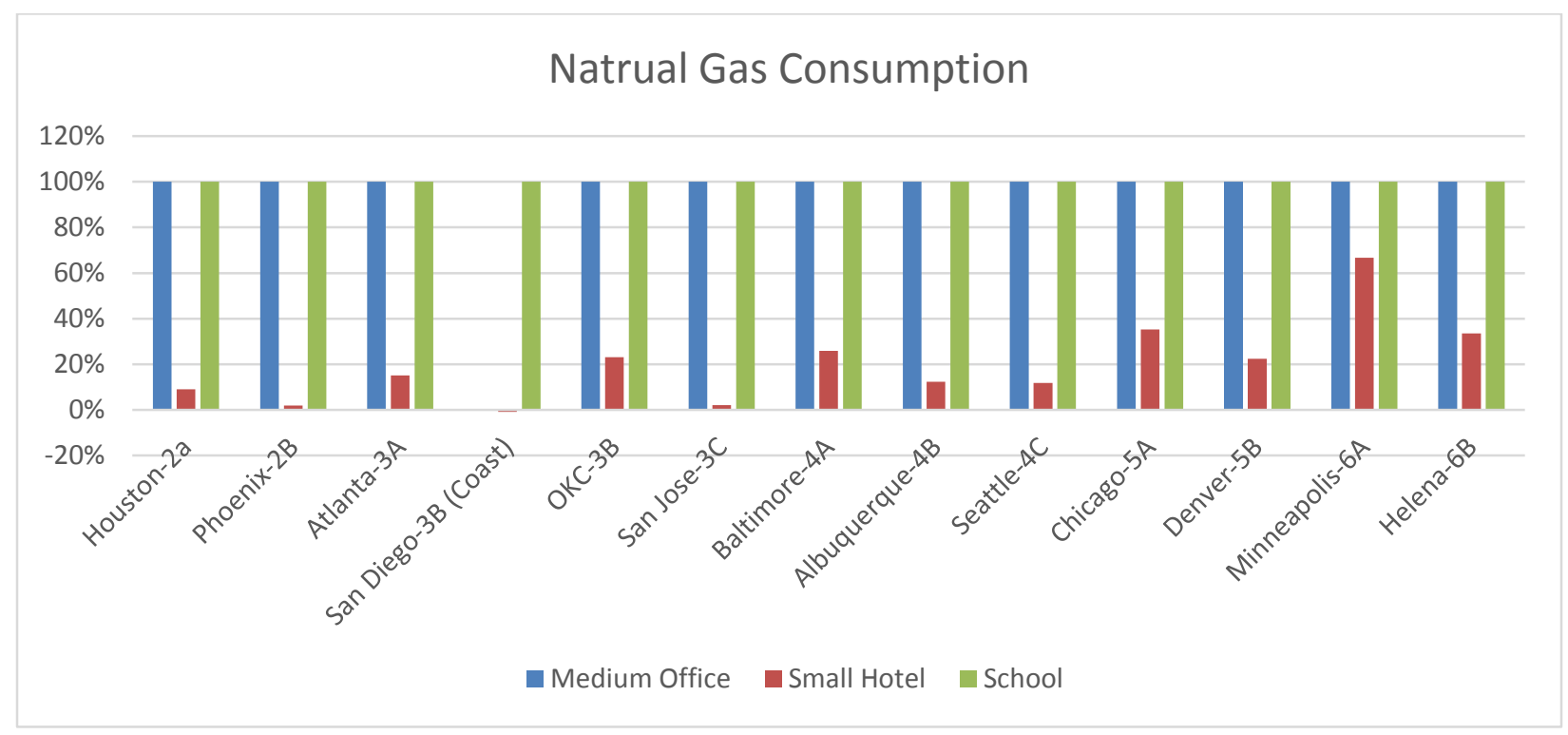

Fig. ES-2. Annual natural gas saving percentages by building types and locations.

Despite having the largest average site energy savings, the secondary school's GHP applications have the lowest average energy cost saving percentage (22\%) among the three buildings (Fig. ES-3). This is because the baseline HVAC system of the secondary school uses only natural gas for space heating. 
Although the GHP system eliminates the use of natural gas for space heating, it does consume electricity to run the heat pump for space heating. Given the currently low natural gas price, the resulting energy cost savings are moderate. GHP applications at the medium office and the small hotel resulted in higher average energy cost saving percentages ( $24 \%$ and $27 \%$, respectively) because the GHP system replaces both the gas-fired furnaces and the electric resistance heating used in the baseline HVAC systems of these buildings. The energy cost savings range from 9 to $49 \%$ for the three buildings at most locations except at Phoenix, AZ and San Diego, CA. Generally, GHP systems can save more energy costs in locations with more heating demand. Figure ES-3 shows that the difference in energy cost saving percentages between the medium office and the small hotel is under $20 \%$ in most locations.

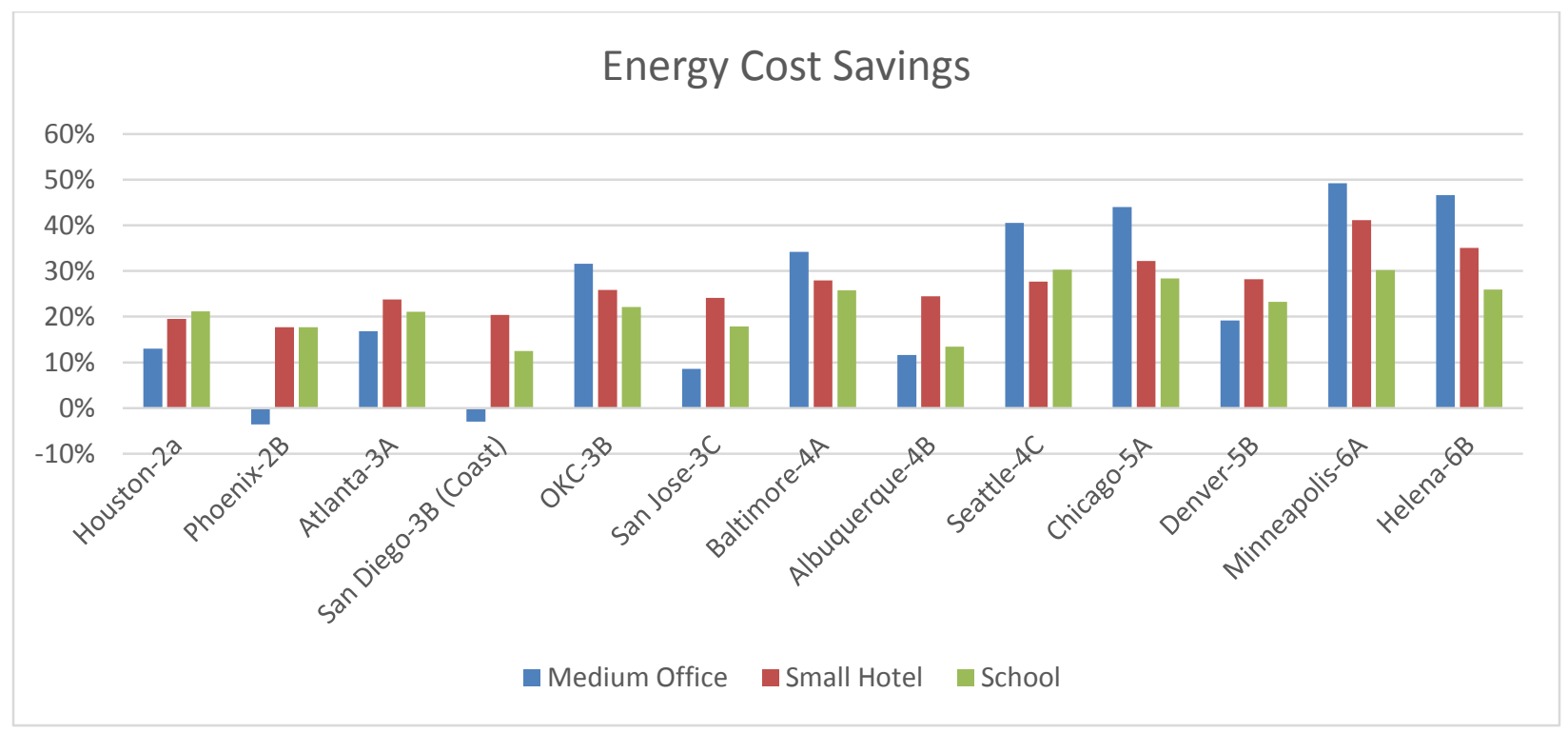

Fig. ES-3. Annual energy cost saving percentages by building types and locations.

Shown in Figs. ES-4 and ES-5, the source energy savings and carbon emission reductions have similar patterns to that of the energy cost savings. The source energy savings and carbon emission reductions range from 9 to $50 \%$ for the three buildings at most locations, except at the two locations discussed previously. Typically, more source energy savings and carbon emission reductions can be expected by replacing electric resistance heaters with GHP systems at locations with larger heating demand. The average source energy saving percentages across all the climate zones are $24 \%$ at the modeled medium office, $27 \%$ at the small hotel, and $23 \%$ at the secondary school. Meanwhile, the average carbon emission reduction percentages across all the climate zones are $24 \%$ at the modeled medium office, $27 \%$ at the small hotel, and $22 \%$ at the secondary school. In warmer climates, the greatest reductions (about 20\%) in source energy consumptions and carbon emissions are seen in the small hotel. The average reduction percentages are $4 \%$ at the medium office and $18 \%$ at the school in these climate zones. In colder climates, the medium office saw the greatest reduction with an average of $38 \%$ compared to $31 \%$ for the small hotel and $24 \%$ for the school. 


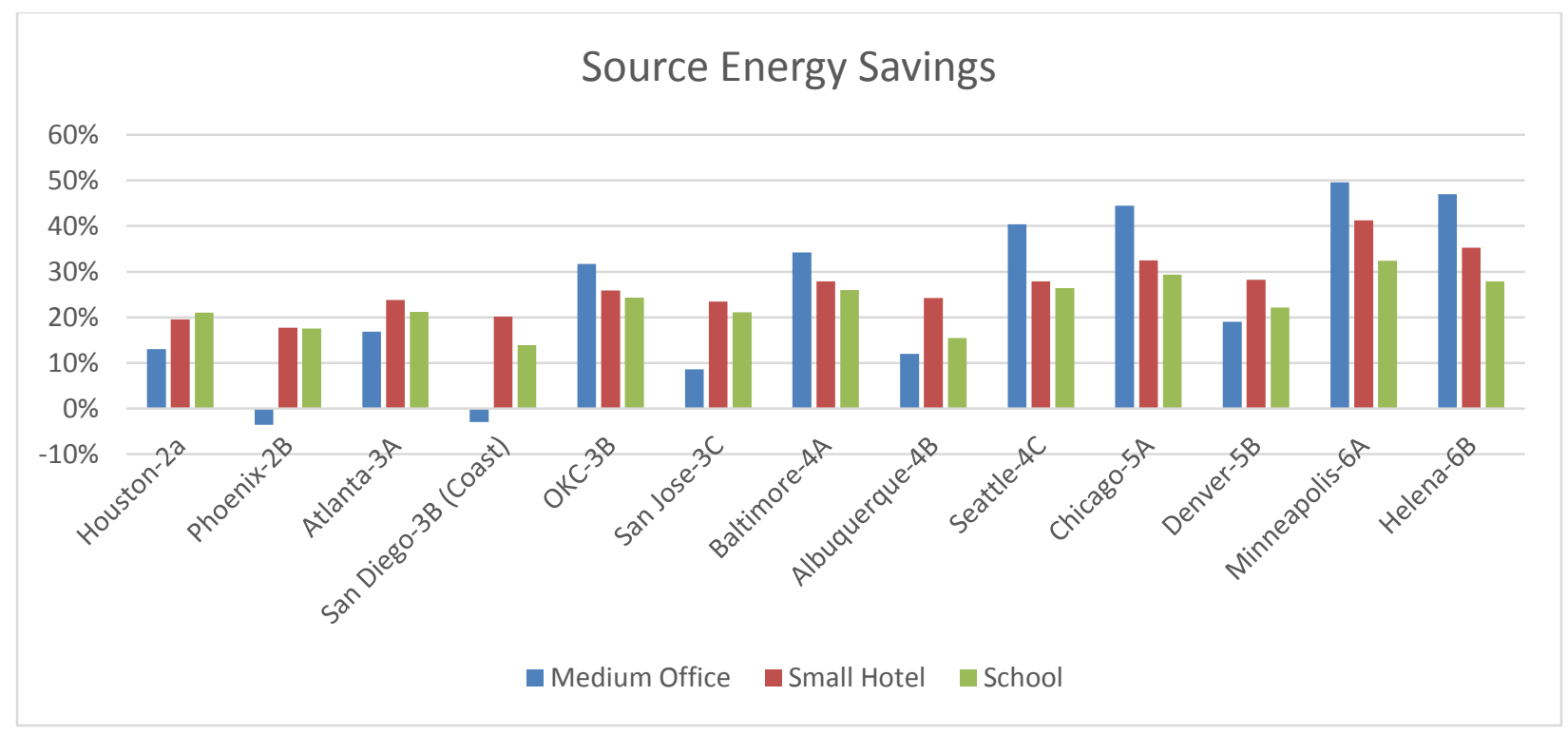

Fig. ES-4. Annual source energy reduction percentages by building types and locations.

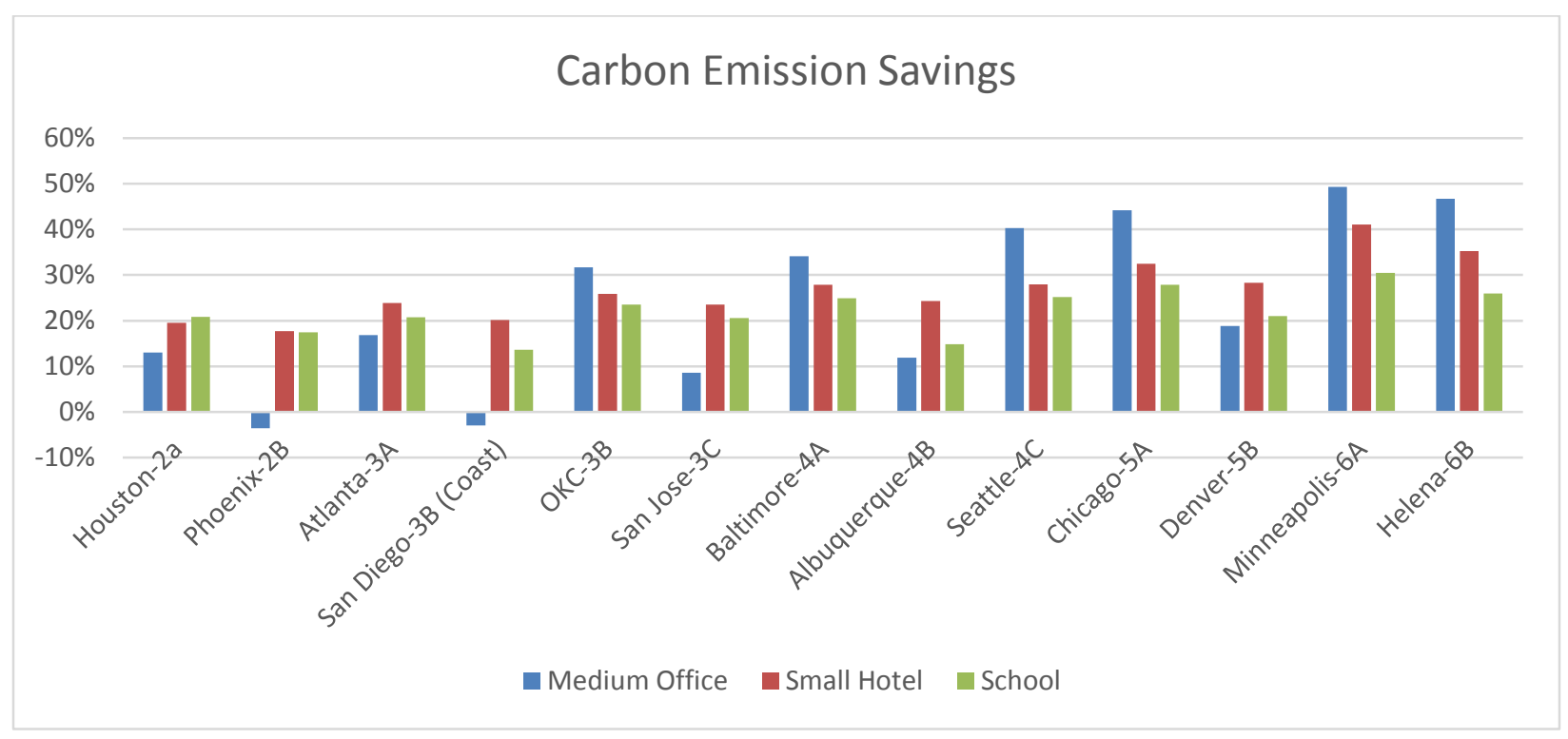

Fig. ES-5. Annual carbon emission reduction percentages by building types and locations.

Figure ES-6 shows that the GHP retrofits reduce peak electricity demand at all the locations. Like electricity savings, the peak demand reduction depends on what baseline HVAC system is retrofitted with the GHP system. Although the peak electricity demand can be reduced by up to $42-48 \%$ in the medium office and small hotel, the reduction is not larger than $22 \%$ at the secondary school where no electric resistance heating is replaced with the GHP. The average peak electricity demand reduction percentages across all the climate zones are $26 \%, 18 \%$, and $13 \%$ at the medium office, small hotel, and secondary school, respectively. 


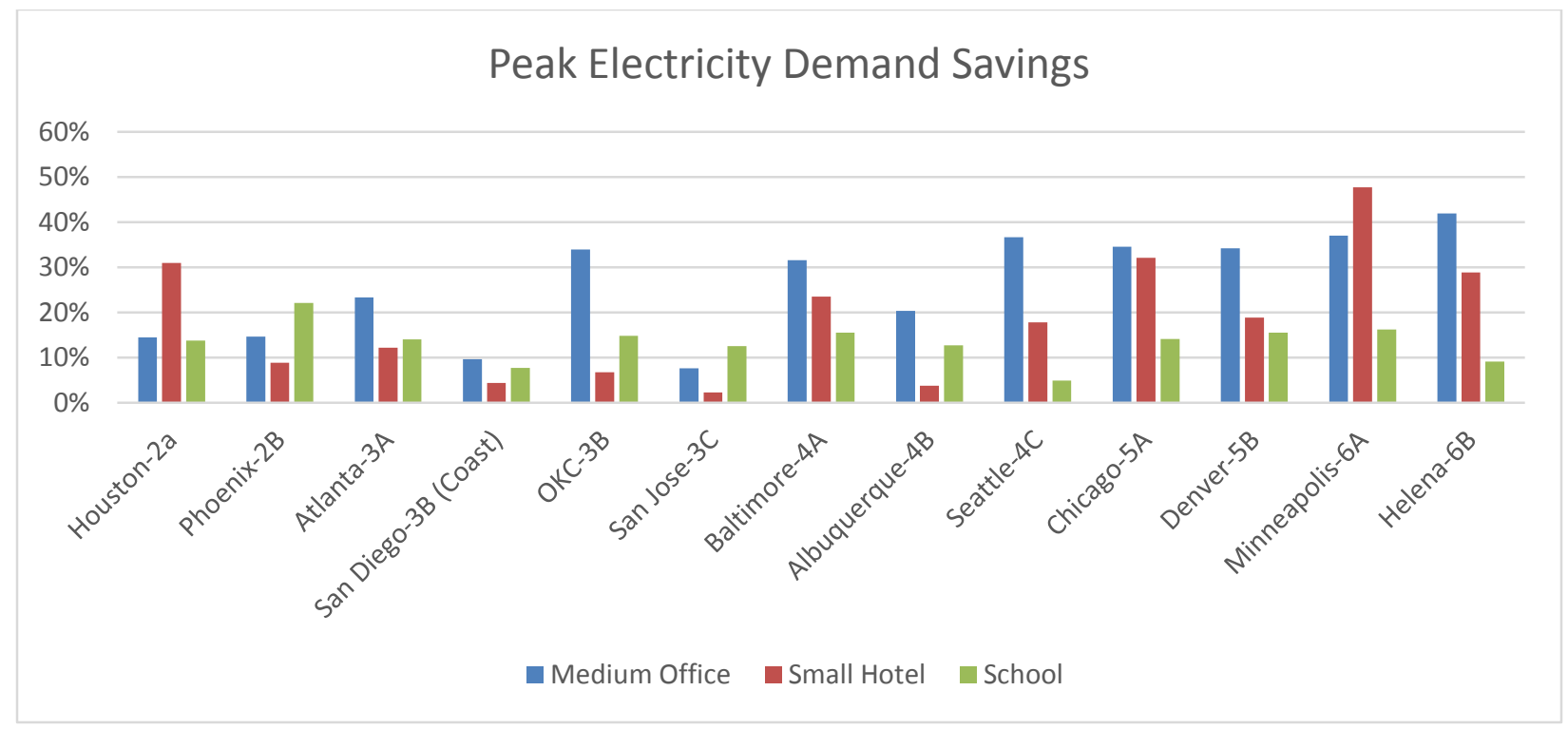

Fig. ES-6. Annual peak electricity demand reduction percentages by building types and locations.

Figure ES-7 compares the nominal size of GHXs (i.e., the length of vertical bore per each cooling ton), which is determined assuming the local ground TC is at the $50^{\text {th }}$ quartile of the ground TC in the state where the building is located. The normalized GHX sizes vary widely from as low as $131 \mathrm{ft} /$ ton (for the medium office at Seattle, WA) to more than $400 \mathrm{ft} /$ ton (for all buildings at Phoenix, AZ). Higher ground TC (i.e., at the $75^{\text {th }}$ quartile) can help reduce the GHX size, but lower ground TC (i.e., at the $25^{\text {th }}$ quartile) can result in larger GHX size.

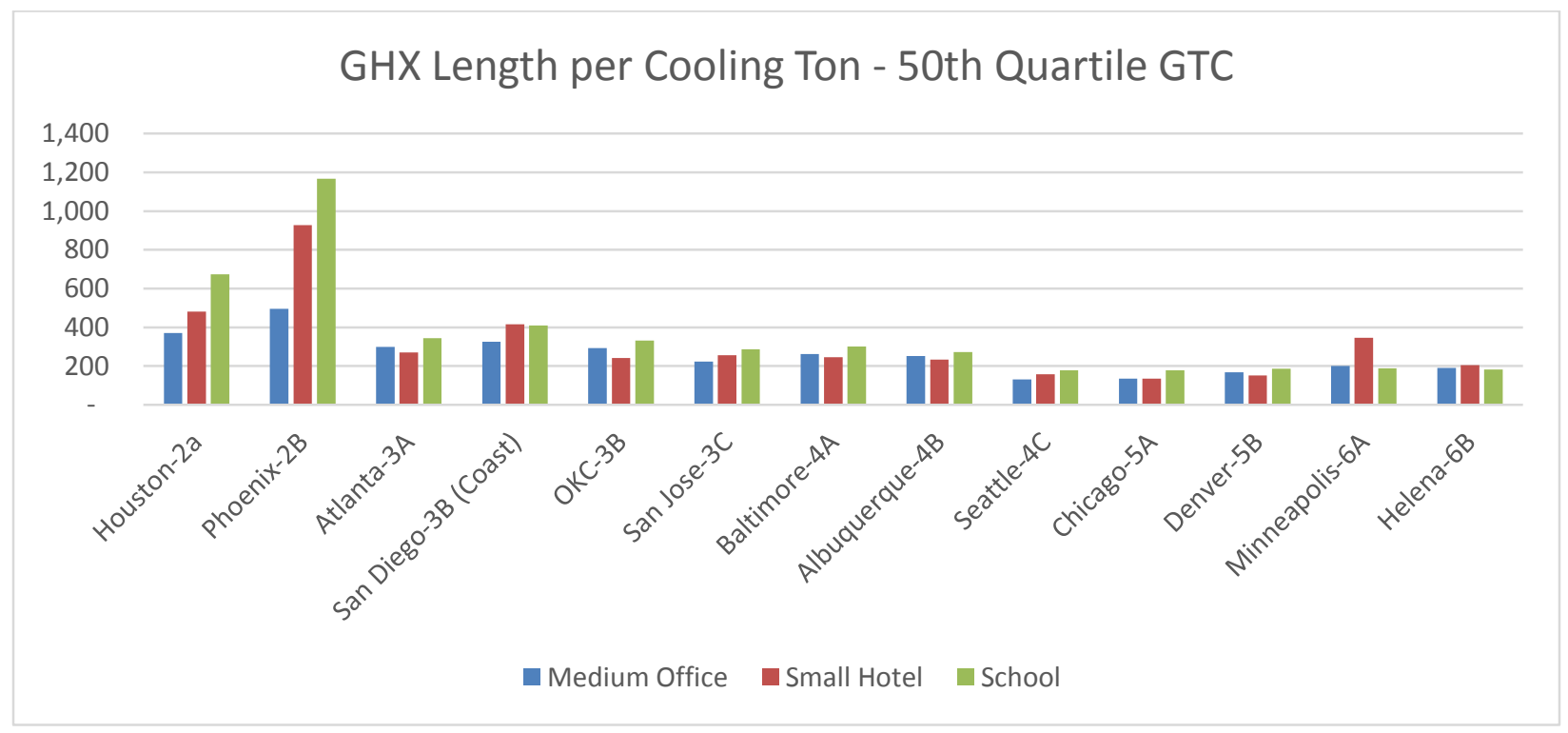

Fig. ES-7. Normalized ground heat exchanger sizes by building types and locations. 


\section{SIMULATIONS OF GHP SYSTEMS AT REPRESENTATIVE COMMERCIAL BUILDINGS}

Geothermal heat pump (GHP) applications in three types of commercial buildings-medium-sized office, small hotel, and secondary school — are simulated with eQUEST, a widely used building energy modeling program that uses the most recent version of the DOE-2 program as its simulation engine (Hirsch et al. 2016). These building types are best fit for GHP applications given the large energy consumptions for space conditioning and the land availability for ground heat exchanger (GHX) installation. The building models are adopted from the commercial reference building models, which the Department of Energy (DOE) developed in conjunction with its national laboratories (NREL 2011). These models represent approximately $70 \%$ of the commercial buildings in the United States.

The simulated GHP system is in a distributed configuration commonly used in the United States. With a distributed GHP system, each building zone is conditioned with an individual water-to-air heat pump (WAHP). Multiple WAHPs are then connected to a GHX through a common water loop. Traditionally, the system uses a two-pipe water loop with a variable-speed central pumping station. Multiple two-stage WAHP units are used in the commercial GHP systems. The nominal cooling efficiency of the two-stage GHP unit has an energy efficiency ratio (EER) of 18.2 at full capacity and an EER of 27 at $76 \%$ of full capacity. The nominal heating efficiency of the two-stage GHP unit has a coefficient of performance (COP) of 4 at full capacity and a COP of 4.5 at $76 \%$ of full capacity. The GHXs used in the simulated GHP systems are closed-loop vertical bore GHXs. These are sized to maintain the fluid temperature from GHXs [the entering fluid temperature (EFT) to the WAHP unit] within the range of $30-80^{\circ} \mathrm{F}\left(-1-27^{\circ} \mathrm{C}\right)$ during the first year of operation with the given building loads, ground thermal properties, and undisturbed ground temperature.

To assess the impacts of weather conditions and ground thermal properties on the performance of the GHP applications, the simulations were conducted with weather data from 13 cities that represent the different climate zones in the United States. In each city, three different ground thermal conductivity (TC) values, representing $20^{\text {th }}, 50^{\text {th }}$, and $75^{\text {th }}$ quartiles of the TCs in each climate zone where the city is located, are used to size the GHXs.

For each building type, the performance of a baseline HVAC system is also simulated at each city. The simulation-predicted performances of both the GHP and the baseline HVAC systems are compared to evaluate the energy savings, carbon emission reductions, energy cost savings, and peak electricity demand reductions that could be achieved by the GHP system. The inputs and results of the simulations are discussed in the following sections.

\subsection{CLIMATE ZONES}

The International Energy Conservation Code has developed a codified climate standard for building science. The categories are given as (1) Very Hot, (2) Hot, (3) Warm, (4) Mixed, (5) Cool, (6) Cold, (7) Very Cold, and (8) Subarctic.

There are three subcategories within this standard: moist climates (A), dry climates (B), and marine climates (C). There are 15 climate zones in the United States. Two of the 15 climate zones, climate zones $1 \mathrm{~A}$ and 7, are excluded from this study because of low populations. The remaining 13 climate zones are represented by cities listed in Table 1 . The latest version of the typical meteorological year (TMY) weather data (Wilcox and Marion 2008) of these cities are used in the simulations. 
Table 1. Representative Cities of Selected Climate Zones

\begin{tabular}{ccc}
\hline Climate zone & Rep. city & Climate \\
\hline 2A & Houston, Texas & Hot, Humid \\
2B & Phoenix, Arizona & Hot, Dry \\
3A & Atlanta, Georgia & Warm, Humid \\
3B-Coast & San Diego, California & Warm, Dry \\
3B & El Paso, Nevada & Warm, Dry \\
3C & San Jose, California & Warm, Marine \\
4A & Baltimore, Maryland & Mixed, Humid \\
4B & Albuquerque, New Mexico & Mixed, Dry \\
4C & Seattle, Washington & Mixed, Marine \\
5A & Chicago, Illinois & Cool, Humid \\
5B & Denver, Colorado & Cool, Dry \\
6A & Minneapolis, Minnesota & Cold, Humid \\
6B & Helena, Montana & Cold, Dry \\
\hline
\end{tabular}

\subsection{GROUND THERMAL CONDUCTIVITY}

The GHX design is dependent on several factors. One important factor is the TC of the ground in which the GHX is installed. This property can significantly affect the size of GHX for given heating and cooling loads, and therefore the cost as well. Taking this factor into account, the available TCs of rock cores in all 50 states (SMU 2016) are used to determine the 25th, 50th, and 75th quartiles of the local ground TC (Table 2) in each state involved in the study. The three ground TC values are used to size the GHX for each building and in each climate zone.

Table 2. Typical Values of Ground Thermal Conductivity in Selected States

\begin{tabular}{llrrr}
\hline Climate zones & State & TC_q25 & TC_q50 & TC_q75 \\
\hline $\mathbf{2 B}$ & AZ & 0.576 & 0.917 & 1.460 \\
3B-Coast, 3C & CA & 0.716 & 1.117 & 1.743 \\
5B & CO & 0.884 & 1.177 & 1.568 \\
3A & GA & 1.068 & 1.243 & 1.448 \\
$\mathbf{5 A}$ & IL & 1.439 & 1.726 & 2.072 \\
$\mathbf{4 A}$ & MD & 0.838 & 1.023 & 1.249 \\
$\mathbf{6 A}$ & MN & 0.766 & 0.997 & 1.298 \\
$\mathbf{6 B}$ & MT & 0.612 & 0.981 & 1.571 \\
$\mathbf{4 B}$ & NM & 0.628 & 0.972 & 1.505 \\
$\mathbf{3 B}$ & OK & 1.058 & 1.364 & 1.759 \\
$\mathbf{2 A}$ & TX & 1.013 & 1.348 & 1.793 \\
$\mathbf{4 C}$ & WA & 1.047 & 1.418 & 1.919 \\
\hline
\end{tabular}




\subsection{UTILITY RATE}

The utility rates for the electric and natural gas used to calculate the energy cost are the 2014 prices obtained from the Energy Information Agency (EIA). ${ }^{1}$ Electricity rates are the annual average in each state over 2014, as they do not vary greatly from month to month. The monthly variation of the natural gas price is taken into account in the energy cost calculation. The utility rates are listed in Table 3 .

Table 3. Utility Rates at Selected States

\begin{tabular}{|c|c|c|c|c|c|c|c|c|c|c|c|c|c|c|}
\hline \multicolumn{15}{|c|}{ Price of Electricity Sold to Commercial Customers (Cents per killa-watt) EIA } \\
\hline & \begin{tabular}{|c|} 
North \\
Carolina
\end{tabular} & Texas & Arizona & Georgia & California & Nevada & Maryland & New Mexico & Washington & Illinois & Colorado & Minnesota & Monatana & Oklahoma \\
\hline 2014 Average & 8.746 & 8.163 & 10.051 & 10.348 & 15.460 & 9.480 & 11.174 & 10.213 & 7.968 & 9.262 & 10.062 & 9.843 & 9.645 & 8.054 \\
\hline \multicolumn{15}{|c|}{ Price of Natural Gas Sold to Commercial Consumers (Dollars per Thousand Cubic Feet) } \\
\hline Month & \begin{tabular}{|c|} 
North \\
Carolina
\end{tabular} & Texas & Arizona & Georgia & California & Nevada & Maryland & New Mexico & Washington & Illinois & Colorado & Minnesota & Monatana & Oklahoma \\
\hline Jan-2014 & 8.36 & 7.23 & 8.74 & 8.94 & 8.81 & 7.19 & 9.67 & 6.84 & 9.09 & 6.83 & 7.39 & 7.84 & 7.81 & 6.09 \\
\hline Feb-2014 & 9.3 & 7.44 & 9.55 & 9.52 & 9.1 & 7.43 & 10.48 & 7.53 & 9.09 & 7.45 & 7.5 & 8.75 & 8.09 & 6.62 \\
\hline Mar-2014 & 9.54 & 8.49 & 10.15 & 9.88 & 10.09 & 7.71 & 10.45 & 8.25 & 8.71 & 10.49 & 7.78 & 9.63 & 8.64 & 7.23 \\
\hline Apr-2014 & 9.13 & 9 & 10.05 & 10.38 & 9.12 & 7.87 & 11.2 & 8.49 & 8.66 & 12.84 & 8.43 & 9.56 & 9.56 & 9.45 \\
\hline May-2014 & 8.7 & 9.38 & 10.29 & 10.8 & 8.98 & 8.2 & 12.39 & 8.29 & 8.85 & 13.01 & 8.72 & 8.4 & 10.49 & 12.52 \\
\hline Jun-2014 & 7.75 & 9.3 & 10.66 & 12.13 & 8.82 & 8.34 & 11.6 & 8.84 & 8.95 & 14.85 & 9.72 & 9.56 & 11.5 & 15.92 \\
\hline Jul-2014 & 10.63 & 9.24 & 10.77 & 11.73 & 9.25 & 9.2 & 12.02 & 9.19 & 9.17 & 15.16 & 11.01 & 9.55 & 11.5 & 16.22 \\
\hline Aug-2014 & 10.3 & 9.02 & 11.1 & 11.5 & 8.73 & 9.6 & 11.1 & 9.03 & 9.23 & 14.66 & 10.96 & 8.65 & 11.11 & 15.9 \\
\hline Sep-2014 & 9.62 & 8.68 & 11.45 & 11.3 & 8.72 & 9.22 & 12.06 & 8.78 & 9.13 & 11.71 & 10.45 & 8.7 & 9.94 & 16.47 \\
\hline Oct-2014 & 9.81 & 8.72 & 11.47 & 11.49 & 8.88 & 9.32 & 10.79 & 8.56 & 8.95 & 8.68 & 8.48 & 8.37 & 9.46 & 15.78 \\
\hline Nov-2014 & 8.73 & 8.12 & 10.95 & 8.79 & 8.5 & 8.98 & 9.37 & 7.73 & 9.27 & 7.14 & 7.92 & 8.04 & 8.19 & 10.47 \\
\hline Dec-2014 & 9.47 & 7.98 & 11.12 & 9.04 & 9.26 & 8.58 & 10.57 & 7.28 & 9.28 & 7.76 & 7.82 & 8.5 & 8.04 & 7.06 \\
\hline
\end{tabular}

\subsection{SIMULATION TOOL AND PROCEDURE}

The computer simulations for the commercial GHP systems are conducted with the eQUEST program, powered by the latest development of the DOE-2.2 program. DOE-2.2 has a model for simulating various vertical-bore closed-loop GHXs, which uses the widely accepted g-function approach developed by Eskilson (1987), a simplified extension for performing hourly simulations (Liu and Hellstrom 2006), and a model for simulating GHP units that uses a two-stage compressor (Liu 2008). Although DOE-2.2 can automatically size the major equipment of conventional HVAC systems for a given building, it cannot do so for the GHX used in the GHP system. It usually requires the user to manually adjust the design parameters of a GHX and run iteratively until a satisfactory GHX size is found. To facilitate this study, a software tool was developed to automate the sizing process.

As shown in Fig. 1, for each representative building at a given location, the automation tool runs two parallel simulations. One is for the GHP system, and the other is for a baseline HVAC system. For the GHP system, it iterates the simulations until a GHX design is found that satisfies the design criteria. The eventual goal is to maintain a maximum leaving water temperature (LWT) from GHX of $80 \pm 1^{\circ} \mathrm{F}$ during first year's operation. For locations with hot climates, the maximum allowed LWT is elevated to $85^{\circ} \mathrm{F}$.

To ensure the two systems provide equivalent space conditioning to the building, the predicted hours when the building's heating and cooling loads were not satisfied (usually referred as the unmet load hours) will be checked after each simulation. If the unmet load hours are greater than $3.4 \%$ of the total runtime of the system, which is the maximum allowed percentage of unmet loads as required by ASHRAE standard 90.1-2004 (ASHRAE 2004), the system capacity will be increased and the simulation will be repeated until the percentage of the unmet load hours is below the maximum allowance.

\footnotetext{
${ }^{1}$ Natural gas price is from https://www.eia.gov/dnav/ng/ng_pri_sum_a_EPG0_PRS_DMcf_a.htm, and electricity price is from https://www.eia.gov/electricity/monthly/epm_table_grapher.cfm?t=epmt_5_6_a
} 


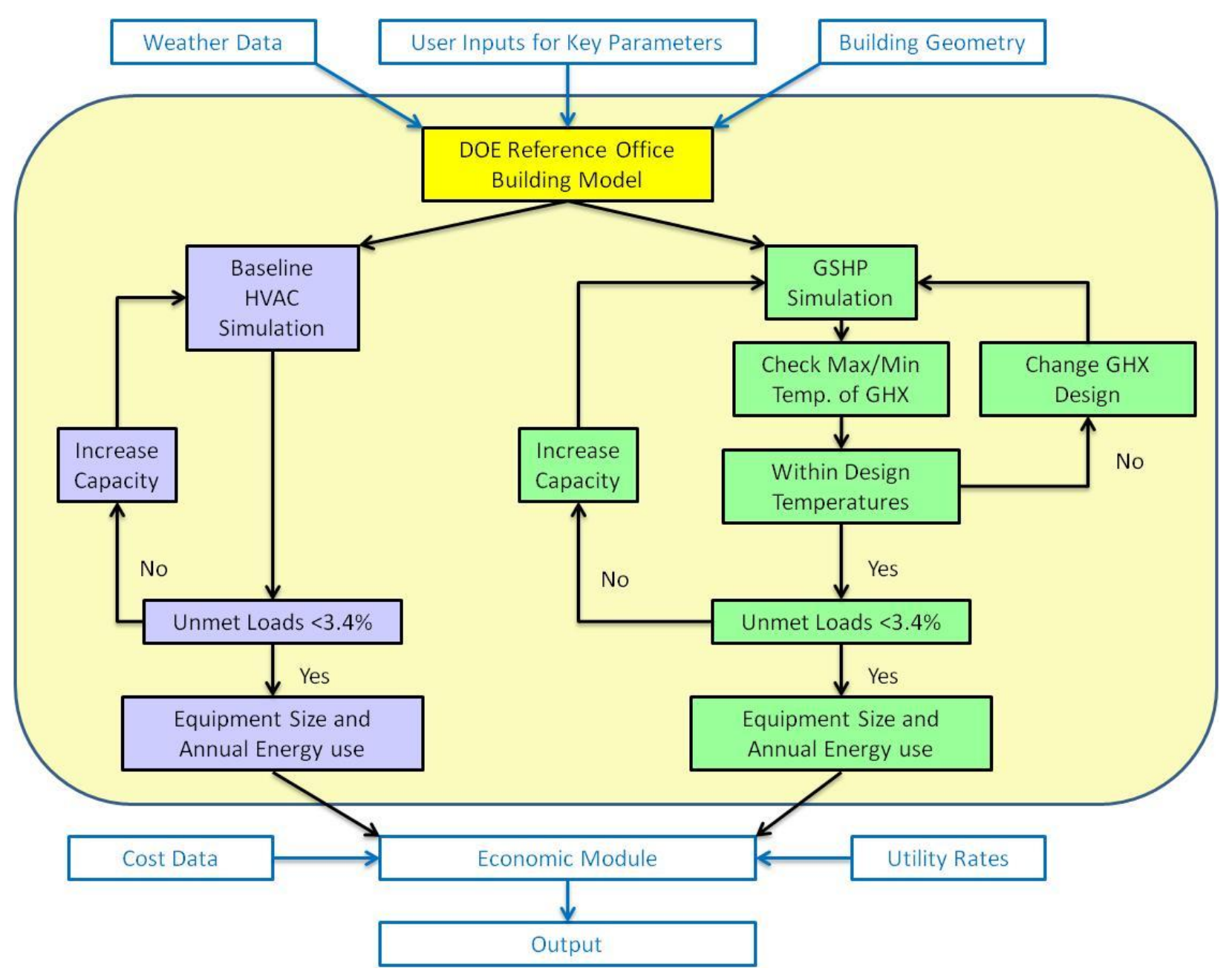

Fig. 1. Linear curve fit of available cost data of packaged VAV systems.

The automation tool automatically runs all the simulations with user-specified weather data and input files, which describe the modeled building and the GHP and the baseline HVAC systems. It sizes the GHX and predicts the energy consumption of the two systems.

\subsection{SIMULATION RESULTS}

\subsubsection{Medium Office}

The modeled medium office is a 53,620 $\mathrm{ft}^{2}$ three-story building (Fig. 2). The baseline HVAC system for this building is a packaged variable air volume (VAV) system, which uses an air-cooled direct expansion refrigeration system to provide space cooling and a natural-gas-fired furnace as the primary heat source. Electric resistance reheat is used at the VAV terminal box in each zone to satisfy various heating and cooling demands. The cooling efficiency of the direct expansion refrigeration system is 3.69 COP. The heating efficiency of the gas furnace is $80 \%$. The VAV system has an air-side economizer, which can use $100 \%$ outdoor air to provide free cooling when the outdoor air is cooler than the room air. A distributed GHP system is used to replace the entire VAV system, which provides individual climate control to each zone of the building and does not need any terminal reheat. The minimum code-compliant outdoor ventilation is provided through each GHP unit, and no air-side economizer is used. 


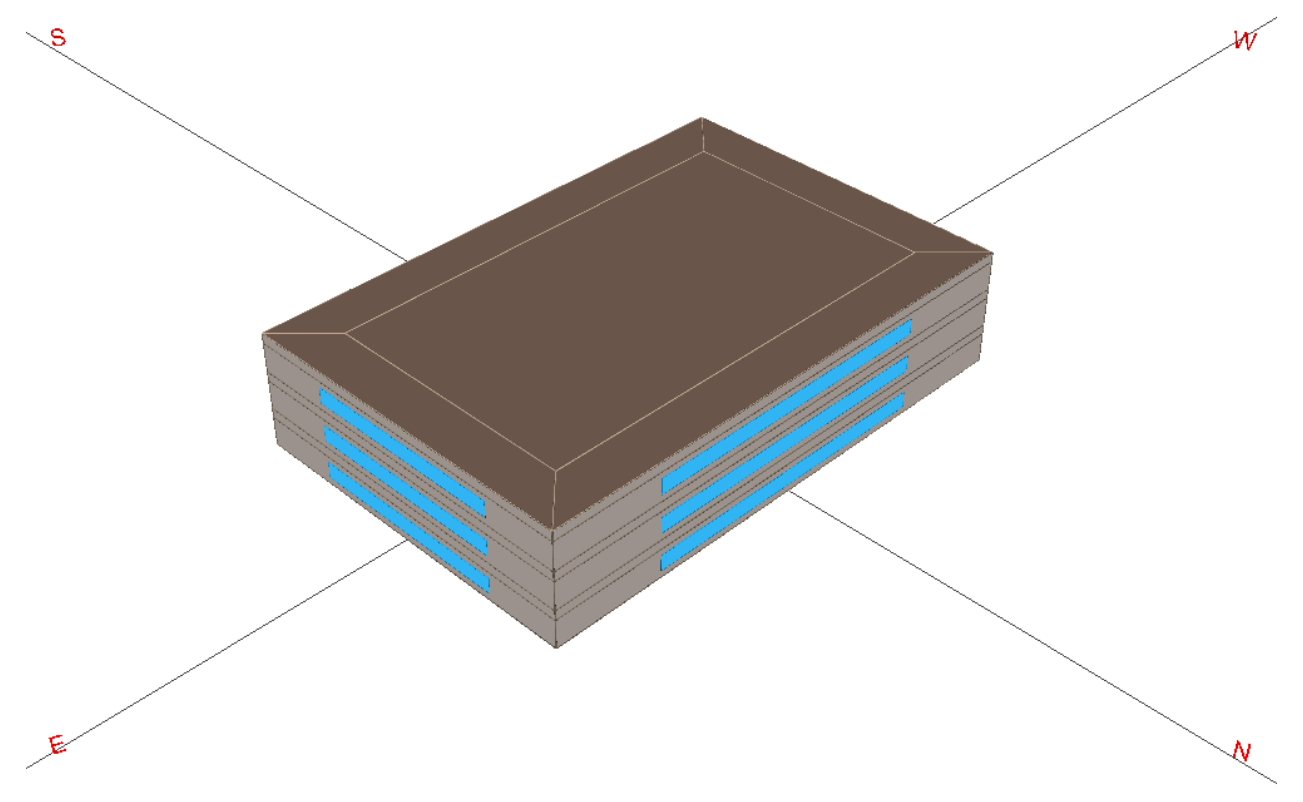

Fig. 2. 3-D rendering of the modeled medium-sized office building.

Simulation results indicate that the GHP system completely eliminates the natural gas consumption for space heating and reduces electricity consumption in most of the investigated locations (Fig. 3). Electricity savings are noticeably higher in cooler climates, with the highest being the cold, moist (6A) climate with electricity savings of $45 \%$. However, GHP systems at the Phoenix, AZ (2B) and San Diego, $\mathrm{CA}$ (3B coast) see a slight increase (3-4\%) in electricity consumption (indicated by the negative percentages). It is due to that the relatively small electricity savings for space cooling in these locations are less than the pumping energy consumed by the GHP system. The average electricity savings for the medium-sized office building is $22 \%$ across all climates.

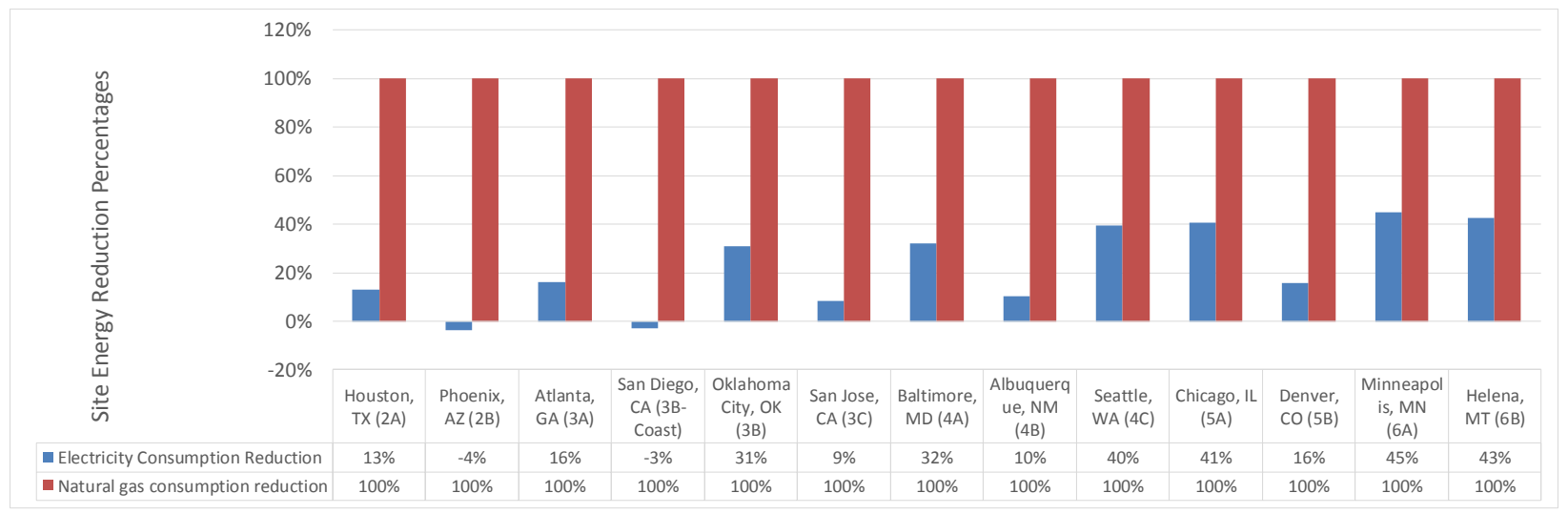

Fig. 3. Site energy saving percentages for the medium office by climate zone.

Source energy is a measure that accounts for the energy consumed on site in addition to the energy consumed during generation and transmission in supplying the energy to the site. Source energy consumption is an important indicator for the environmental performance of a building energy system. Source energy consumption and the associated carbon emissions are calculated based on the simulationpredicted site energy consumptions and the appropriate conversion factors (NREL 2007). The energy costs of both the GHP and the baseline HVAC system are calculated with the simulation-predicted site 
energy consumptions and the utility rates introduced above. As shown in Fig. 4, GHP systems reduce source energy consumption, carbon emissions, and energy cost in 11 of the 13 locations. The two exceptions are Phoenix, AZ, and San Diego, CA, which have increased electricity consumption and few savings in natural gas consumption. The reductions in source energy consumption, carbon emission, and energy cost at each investigated location are identical, with an average of $24 \%$ across all climates. Though savings are typically higher in cooler climates, GHP systems at Albuquerque, NM, and Denver, CO, are exceptions to the rule. One possible explanation would be that the air-side economizer of the VAV system is more effective with the dry and cool air in these two locations.

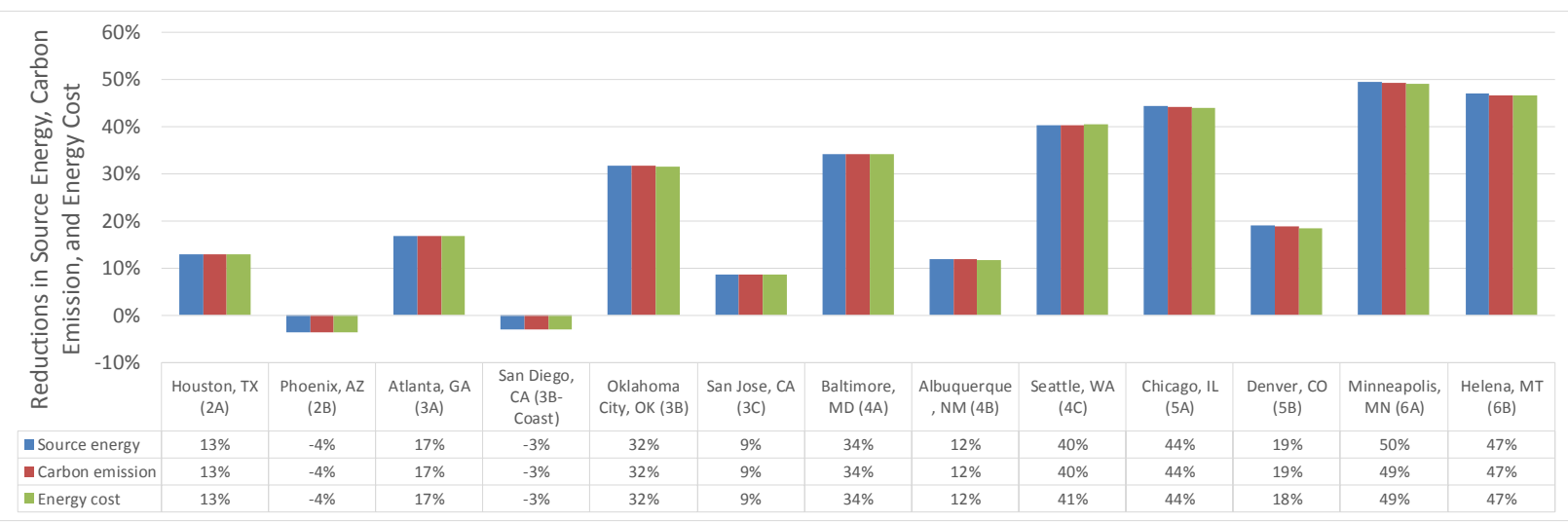

Fig. 4. Source energy, carbon emission, and energy cost reduction percentages for the medium office by climate zone.

Peak electricity demand is an important metric for electricity consumers and providers. If this demand is high, it could burden the power grid and raise electricity cost to consumers. Electricity providers spend large amounts of money accommodating this peak demand and thus have a vested interest in its reduction. The simulation results indicate that the GHP system reduces peak electricity demand by $26 \%$ on average across all the 13 locations while satisfying all the space heating and cooling demands of the medium office building (Fig. 5). Even in climates where electricity consumption savings are negative, there is a decrease in peak demand. In cold climates, the peak electricity demand is reduced by $30 \%$ to $40 \%$, because of the higher cooling efficiency resulting from lower supply water temperature from the GHX.

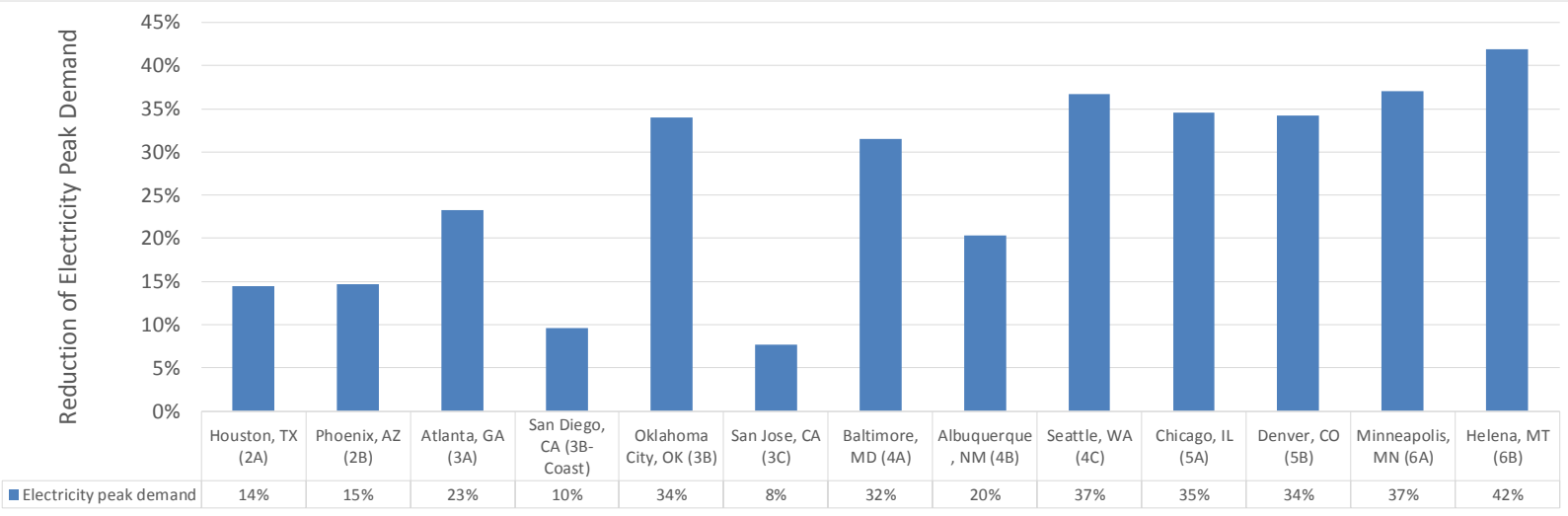

Fig. 5. Peak electric demand reduction percentages for the medium office by climate zone. 


\subsubsection{Small Hotel}

The modeled small hotel is a 40,095 $\mathrm{ft}^{2}$ four-story building (Fig. 6). The baseline HVAC system for this building includes four parts: (1) packaged air-conditioners with a natural-gas-fired furnace for common areas (i.e., front lounge and meeting rooms), (2) a dedicated makeup air unit (MAU) to provide conditioned outdoor air to each guest room, (3) packaged air-conditioner with an electric resistance heater for guest rooms and corridors, and (4) unit heaters with electric resistance for stair cases and storage areas. All the air-conditioners have a 4.0 COP (or 13.7 EER) cooling efficiency, and all the gas furnaces have a $79 \%$ heating efficiency. In the alternative case, a distributed GHP system replaces all the packaged air-conditioners (with either a gas-fired furnace or electric resistance heater) used in the common areas and guest rooms. The MAU, packaged air-conditioners (with electric resistance heater) in the corridors, and unit heaters remain intact.

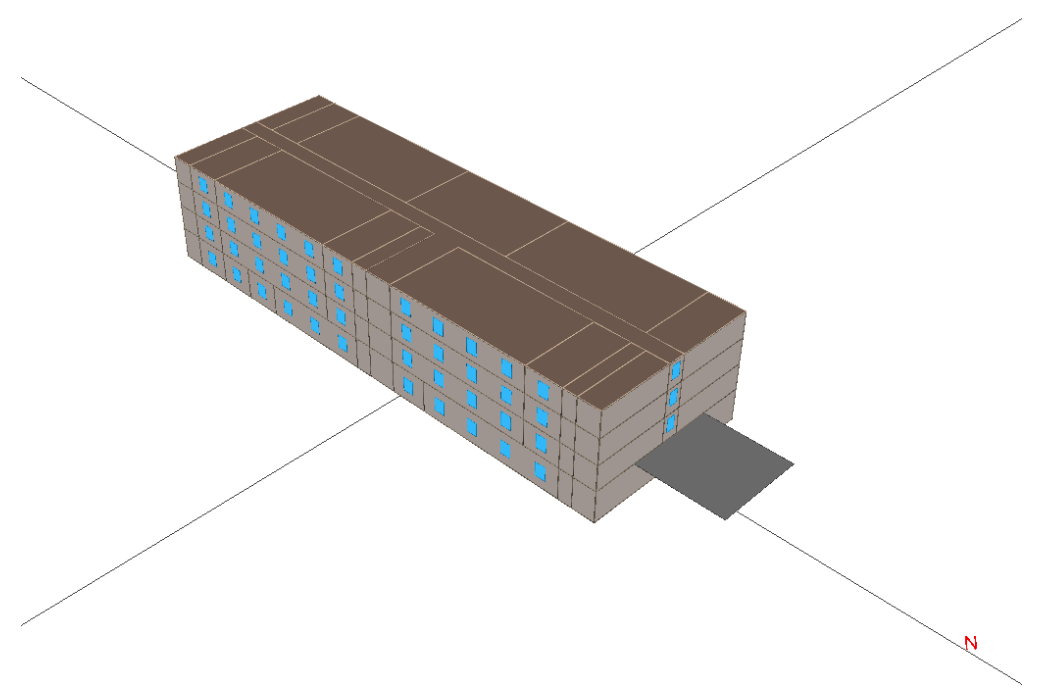

Fig. 6. 3-D rendering of the modeled small hotel building.

Simulation results indicate that the GHP system reduces electricity consumption in all the locations (Fig. 7). The average electricity savings across all climates is $27 \%$ for the small hotel. Electricity savings are higher in cooler climates with up to $35-38 \%$ reduction in electricity consumption in Minneapolis, MN (6A) and Helena, MT (6B). The variable-speed fan used in the two-stage WAHP units of the GHP system contributed a significant portion to the electricity savings. The GHP system also reduces the natural gas consumptions by replacing the gas-fired furnaces serving the common areas of the hotel. Because the original gas-fired MAU warms up the outdoor makeup air, there are still some natural gas consumptions in the GHP system. The reduction percentage of natural gas consumption increases with the increase of space heating demands, and it is negligible at locations with little heating demand (e.g., San Diego, CA). 


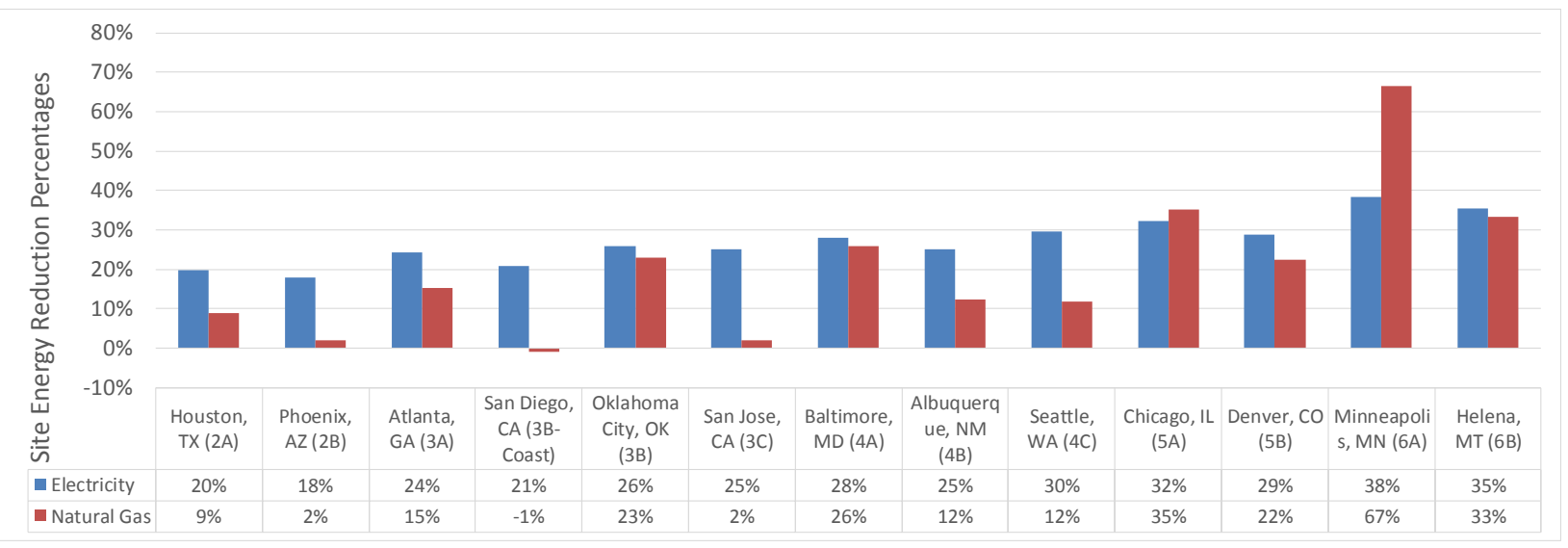

Fig. 7. Site energy saving percentages for the small hotel by climate zone.

As shown in Fig. 8, GHP systems reduce source energy consumption, carbon emissions, and energy cost at all 13 locations. In general, the GHP system results in more reductions in source energy consumption, carbon emission, and energy cost at cooler climates. These reductions are identical for each location, with an average of $27 \%$ across all climates.

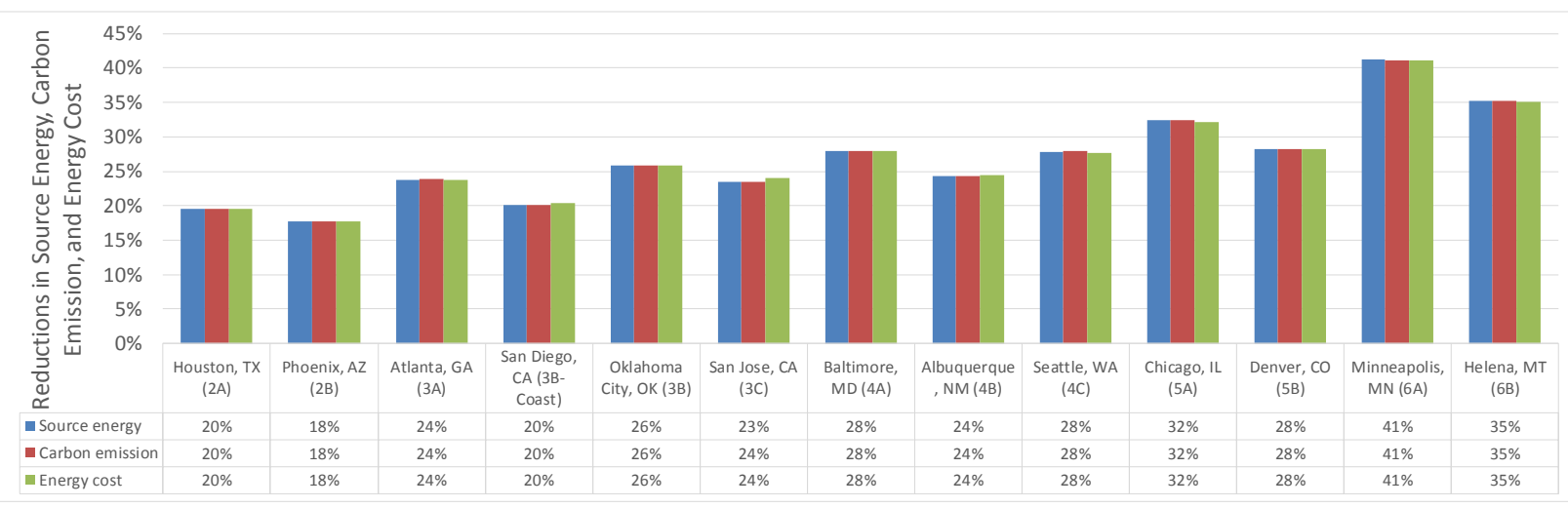

Fig. 8. Source energy, carbon emission, and energy cost reduction percentages for the small hotel by climate zone.

On average, the GHP system reduces peak electricity demand by $18 \%$ at the small hotel across all locations (Fig. 9). In cold climates, peak electricity demand reduces by up to $48 \%$ because the WAHP units replaced the electric resistance space heating. However, the peak demand reduction is less than 5\% at locations with mild weather (San Diego, CA and San Jose, CA). This phenomenon occurs because there is not much difference between the ambient air temperature and the supply temperature from a GHX at these locations. 


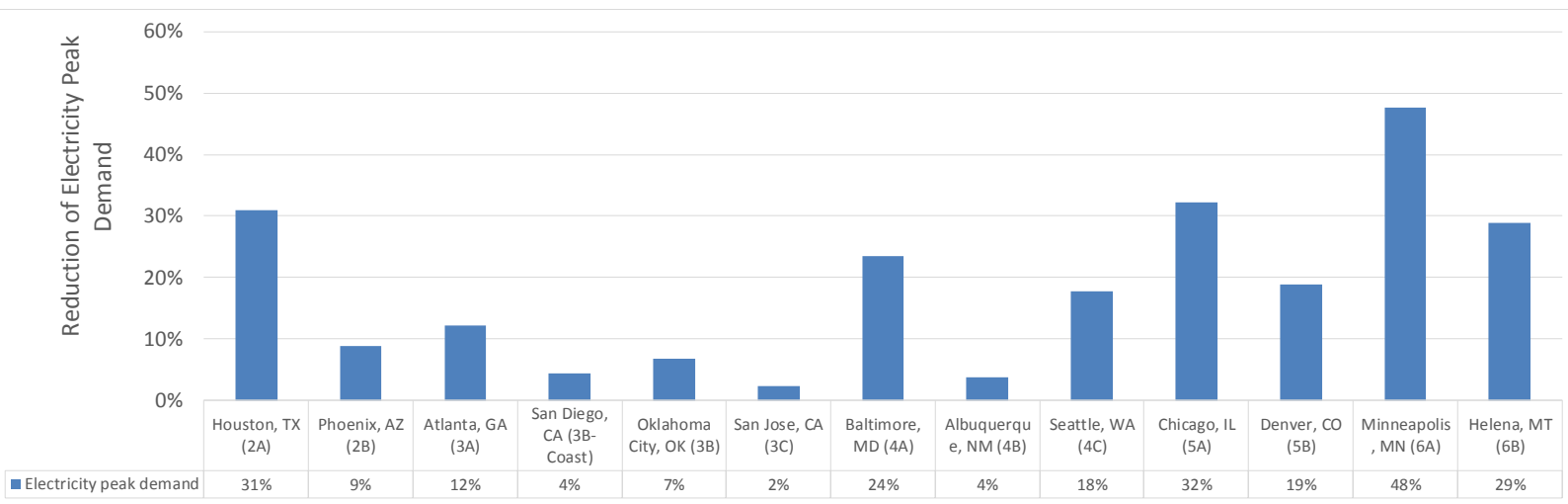

Fig. 9. Peak electric demand reduction percentages for the small hotel by climate zone.

\subsubsection{Secondary School}

The modeled secondary school is a $210,954 \mathrm{ft}^{2}$ two-story building (Fig. 10). The baseline HVAC system for this building includes two parts: VAV systems for the pods and packaged single-zone (PSZ) systems for the gym, auditorium, kitchen, and cafeteria. The VAV systems use the chilled water produced by an air-cooled chiller to provide space cooling, and they use the hot water produced by a natural-gas-fired boiler to provide space heating. The PSZ systems use an air-cooled direct expansion refrigeration system to provide space cooling and a natural-gas-fired furnace to provide space heating. The cooling efficiency of the baseline equipment (i.e., the air-cooled chiller and the air-cooled direct expansion refrigeration system) is $3.3 \mathrm{COP}$ (11.3 EER), and the heating efficiency of the gas-fired boiler/furnace is $80 \%$. All the VAV and PSZ systems have an air-side economizer. Alternatively, a distributed GHP system replaces the entire baseline system and provides individual climate control to each zone. Outdoor air (OA) ventilation is provided by each WAHP unit based on a schedule for minimum OA supply, which is the same as that used in the baseline HVAC system.

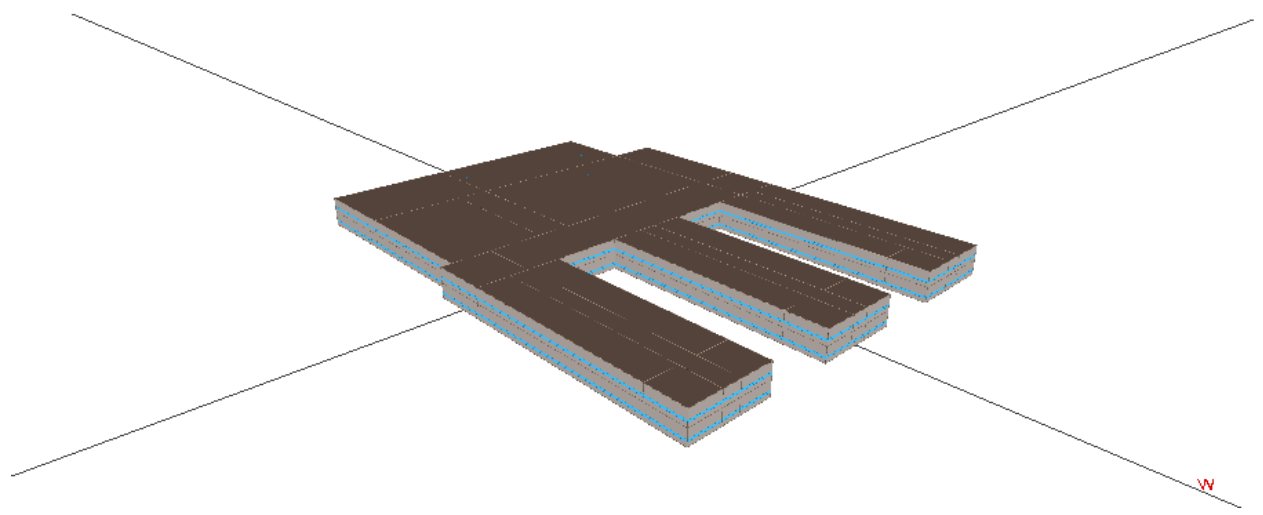

Fig. 10. 3-D rendering of the modeled secondary school building.

Because the GHP system replaces the entire baseline VAV system in the secondary school, the natural gas consumption for space heating is completely eliminated. The GHP retrofit reduces HVAC-related electricity consumptions at all of the 13 locations except at Minneapolis, MN (6A) and Helena, MT (6B), where the increased electricity consumption for providing space heating with the GHP system offsets the reduced electricity consumption for space cooling (Fig. 11). Because the terminal reheat of the baseline VAV system for the secondary school does not use any electric resistance heaters, the electricity savings achieved by the GHP system is lower than that in the medium office and the small hotel. The average electricity savings across all climates is only $5 \%$ for the secondary school. 


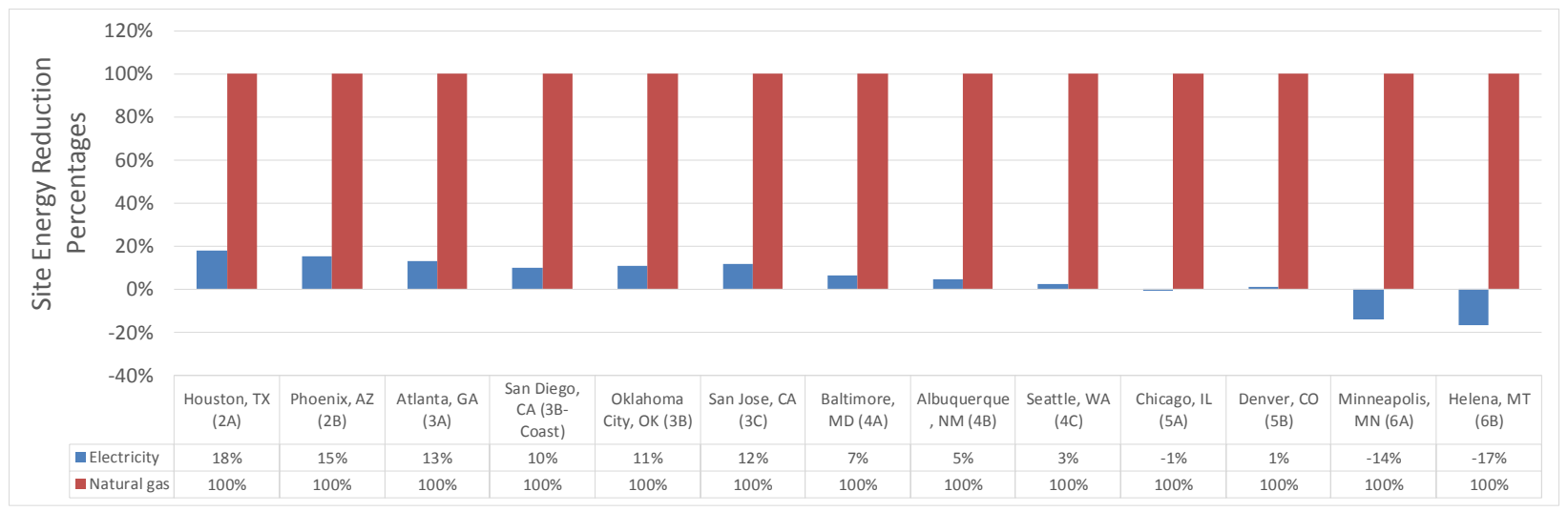

Fig. 11. Site energy saving percentages for the secondary school by climate zone.

As shown in Fig. 12, GHP systems reduce source energy consumption, carbon emissions, and energy cost for the secondary school at each location. The average reductions across all climates are $23 \%$ for source energy consumption, $22 \%$ for carbon emissions, and $22 \%$ for energy cost. In general, more reductions can be achieved at cooler climates.

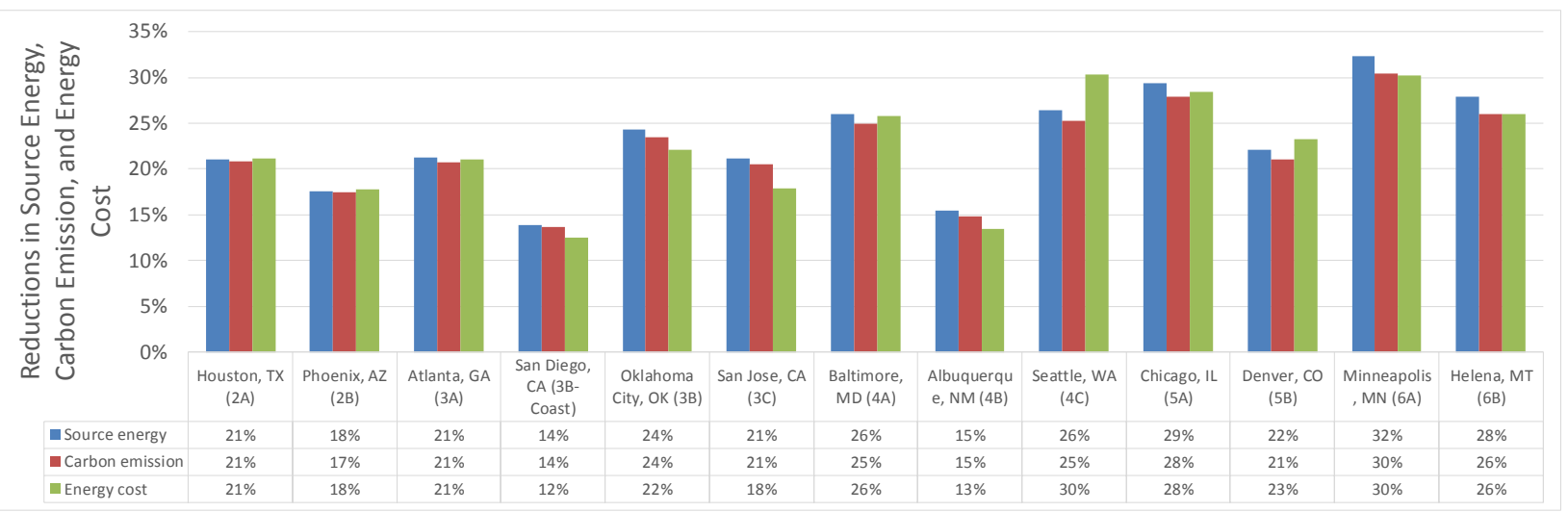

Fig. 12. Source energy, carbon emission, and energy cost reduction percentages for the secondary school by climate zone.

The GHP system reduces peak electricity demand for the secondary school at each location (Fig. 13). The peak reduction percentages range from 5\% at Seattle, WA, to 22\% at Phoenix, AZ. The average peak electricity demand reduction is $13 \%$ across all the climates. 


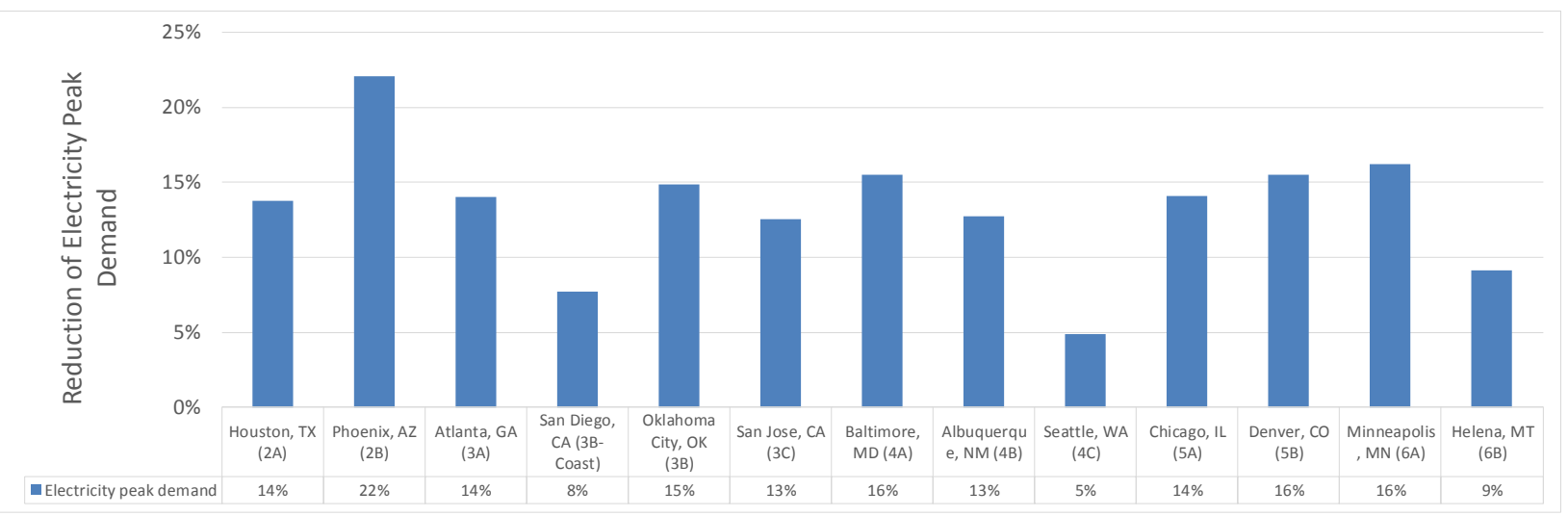

Fig. 13. Peak electric demand reduction percentages for the small hotel by climate zone.

\section{COST MODELS FOR GHP AND CONVENTIONAL HVAC SYSTEMS}

The cost models for GHP and conventional HVAC systems account for different system capacities for a given building at various climates. In addition, for GHP system, the model also accounts for the needed size of GHXs, which is affected not only by the system capacity but also by the ground thermal properties at a given location (e.g., the undisturbed ground temperature and ground TC). The cost models use the normalized costs of major components of the GHP and conventional HVAC systems, which are obtained from an extensive review of available cost data in publically available literature and databases.

The installed costs of GHP and conventional HVAC systems are calculated with the cost models using the simulation-predicted system heating and cooling capacities.

- The total cost of a GHP system is the sum of the installed cost of all the water source heat pump equipment, the GHXs, and the rest of the system, including ductwork and water distribution system (i.e., hydronic piping and circulation pumps).

- The total cost of a packaged VAV system is the sum of the installed costs of the packaged HVAC equipment, ductwork, and standard controls.

- The total cost of a large VAV system, which uses a chiller and a boiler to produce chilled and hot water, is the sum of the installed costs of the chiller, boiler, air-handling unit and ductwork, water distribution system, and standard controls.

- The total cost of a packaged terminal heating and cooling system (i.e., air-source heat pump or airconditioner with an electric/gas furnace) is the sum of the installed cost of the packaged terminal heating and cooling equipment, and ductwork if it is applicable.

\subsection{COMPONENT COST OF GHP SYSTEM}

\subsubsection{Ground Heat Exchanger}

GHX cost was taken from a previous report (Battocletti and Glassley 2013) in which various GHP installations were surveyed for cost information. The GHX cost data listed in Table 4 were leveled using the cost-of-living index based on the reported zip code of each survey. Most of survey responses provided cost for vertical closed-loop GHXs. The median normalized cost of vertical closed-loop GHXs in the four 
census regions in the United States ranges from $\$ 12.99$ per linear foot of the vertical bore (in the Midwest) to $\$ 16.03$ per foot (in the Northeast).

Table 4. Cost of GHXs by Loop Type and Census Region

\begin{tabular}{|c|c|c|c|c|}
\hline Census Region & Loop Type & Number Reported & \multicolumn{2}{|c|}{ Median price/ft } \\
\hline Midwest & Vertical & 31 & $\$$ & 12.99 \\
\hline Midwest & Horizontal trenching & 11 & $\$$ & 12.12 \\
\hline Midwest & horizontal drilling & 5 & $\$$ & 7.13 \\
\hline Midwest & pond/lake & 1 & $\$$ & 2.39 \\
\hline Northeast & Vertical & 21 & $\$$ & 16.03 \\
\hline Northeast & direct exchange & 1 & $\$$ & 3.00 \\
\hline Northeast & horizontal trenching & 1 & $\$$ & 2.33 \\
\hline Northeast & open & 1 & $\$$ & 13.88 \\
\hline Northeast & pond/lake & 1 & $\$$ & 2.32 \\
\hline South & Vertical & 26 & $\$$ & 14.94 \\
\hline South & direct exchange & 2 & $\$$ & 8.36 \\
\hline South & horizontal drilling & 3 & $\$$ & 12.47 \\
\hline South & horizontal trenching & 3 & $\$$ & 9.24 \\
\hline West & Vertical & 8 & $\$$ & 14.64 \\
\hline West & Horizontal trenching & 4 & $\$$ & 11.38 \\
\hline West & horizontal drilling & 2 & $\$$ & 6.25 \\
\hline West & direct exchange & 1 & $\$$ & 10.06 \\
\hline West & open & 1 & $\$$ & 44.69 \\
\hline
\end{tabular}

\subsubsection{GHP Equipment}

The water source heat pump units used in distributed GHP systems usually have a cooling capacity no greater than 5 tons. RSMeans ${ }^{2}$ (2016) provides installed cost data (including the water source heat pump, the labor for installation, and the overhead and profit, abbreviated as O\&P) for water source heat pump units with 1,2, and 5 ton cooling capacity. As listed in Table 5, the cost per ton decreases as the cooling capacity increases. Linear interpolation between the costs of the three cooling capacities is used to estimate the cost of water source heat pump units with other capacities. The total cost of water source heat pump units of a GHP system is calculated based on the unit cost and the number of water source heat pump units in each category of the cooling capacities.

Table 5. Cost of Water Source Heat Pump by Cooling Capacity

\begin{tabular}{|c|c|c|c|c|c|c|c|c|c|c|c|c|c|c|}
\hline cooling & heating & Unit & Bar & & Bare & & Bare Equipment & Bare Total & Tot & Cost O\&P & Tot & Cooling & & st/MBH \\
\hline & 1 & 12 \$/each & $\$$ & $1,775.00$ & $\$$ & 435.00 & $\$$ & $\$ 2,210.00$ & $\$$ & $2,610.00$ & $\$$ & $2,610.00$ & $\$$ & 217.50 \\
\hline & 2 & 19 \$/each & $\$$ & $2,200.00$ & $\$$ & 515.00 & $\$$ & $\$ 2,715.00$ & $\$$ & $3,200.00$ & $\$$ & $1,600.00$ & $\$$ & 168.42 \\
\hline & 5 & 29 \$/each & $\$$ & $3,275.00$ & $\$$ & 970.00 & $\$$ & $\$ 4,245.00$ & $\$$ & $5,075.00$ & $\$$ & $1,015.00$ & $\$$ & 175.00 \\
\hline
\end{tabular}

\subsubsection{Ductwork}

According to RSMeans, the cost of a multi-zone ductwork is $\$ 2,802$ per cooling ton, which includes all the material, labor, overhead and profit for the ductwork installation.

\footnotetext{
${ }^{2}$ RSMeans is North America's leading supplier of construction cost information. A product line of The Gordian Group, RSMeans ${ }^{\circledR}$ provides accurate and up-to-date cost information that helps owners, developers, architects, engineers, contractors, and others to carefully and precisely project and control the cost of both new building construction and renovation projects.
} 


\subsubsection{Water Distribution System}

RSMeans has data for the hydronic piping installation cost, which is based on the material, diameter, length, and insulation level of the pipe. It also has cost data for circulation pumps based on size. However, a hydronic piping system design for the modeled buildings is necessary to estimate the cost of the water distribution system.

\subsection{COMPONENT COST OF CONVENTIONAL HVAC SYSTEM}

\subsubsection{Heating and Cooling Equipment}

The multi-zone packaged VAV system has electric cooling, natural gas heating, and an air-side economizer and is the baseline HVAC system for medium office. RSMeans provided the cost data for this system (Table 6). Similar to the water source heat pumps, the cost per ton of HVAC equipment of a packaged VAV system (excluding ductwork) decreases as the cooling capacity increases (i.e., from $\$ 5,138 /$ ton for a 15 ton equipment to $\$ 2,566 /$ ton for a 105 ton equipment). For packaged VAV systems with a cooling capacity within the range of 15 to 105 tons, their HVAC equipment cost is estimated with a correlation between the total installed cost and the cooling capacity, which is derived based on the available RSMeans data using a third-order polynomial curve fit (Fig. 14). For packaged VAV systems with larger cooling capacities, the HVAC equipment cost is estimated by extrapolating a linear curve fit of the available RSMeans data (Fig. 15).

Table 6. Cost of Multi-Zone Packaged VAV System by Cooling Capacity

\begin{tabular}{|c|c|c|c|c|c|c|c|c|c|c|c|c|}
\hline \multicolumn{5}{|c|}{ Multizone, electric cool, gas heat, economizer } & \multirow[b]{2}{*}{ Bare Equipment } & \multirow[b]{2}{*}{ Bare Total } & \multirow{2}{*}{\multicolumn{2}{|c|}{ Total Cost O\&P }} & \multirow{2}{*}{\multicolumn{2}{|c|}{ Total Cost/Ton Cooling }} & \multirow{2}{*}{\multicolumn{2}{|c|}{ Total Cost/MBH }} \\
\hline cooling & heating & Unit & Bare Material & Bare Labor & & & & & & & & \\
\hline 15 & 360 & $\$ /$ each & $\$ 66,000.00$ & $\$ 3,025.00$ & $\$$ & $\$ 69,025.00$ & $\$$ & $77,075.00$ & $\$$ & $5,138.33$ & $\$$ & 214.10 \\
\hline 20 & 360 & $\$ /$ each & $\$ 71,000.00$ & $\$ 3,475.00$ & $\$$ & $\$ 74,475.00$ & $\$$ & $83,725.00$ & $\$$ & $4,186.25$ & $\$$ & 232.57 \\
\hline 40 & 540 & $\$ /$ each & $\$ 125,000.00$ & $\$ 6,575.00$ & $\$$ & $\$ 131,575.00$ & $\$$ & $147,425.00$ & $\$$ & $3,685.63$ & $\$$ & 273.01 \\
\hline 50 & 540 & $\$ /$ each & $\$ 155,000.00$ & $\$ 8,225.00$ & $\$$ & $\$ 163,225.00$ & $\$$ & $182,900.00$ & $\$$ & $3,658.00$ & $\$$ & 338.70 \\
\hline 70 & 1500 & \$/each & $\$ 168,000.00$ & $\$ 11,500.00$ & $\$$ & $\$ 179,500.00$ & $\$$ & $202,300.00$ & $\$$ & $2,890.00$ & $\$$ & 134.87 \\
\hline 80 & 1500 & \$/each & $\$ 192,000.00$ & $\$ 13,200.00$ & $\$$ & $\$ 205,200.00$ & $\$$ & $230,900.00$ & $\$$ & $2,886.25$ & $\$$ & 153.93 \\
\hline 90 & 1500 & $\$ /$ each & $\$ 201,000.00$ & $\$ 14,800.00$ & $\$$ & $\$ 215,800.00$ & $\$$ & $243,800.00$ & $\$$ & $2,708.89$ & $\$$ & 162.53 \\
\hline 105 & 1500 & $\$ /$ each & $\$ 222,000.00$ & $\$ 16,800.00$ & $\$$ & $\$ 238,800.00$ & $\$$ & $269,400.00$ & $\$$ & $2,565.71$ & $\$$ & 179.60 \\
\hline
\end{tabular}

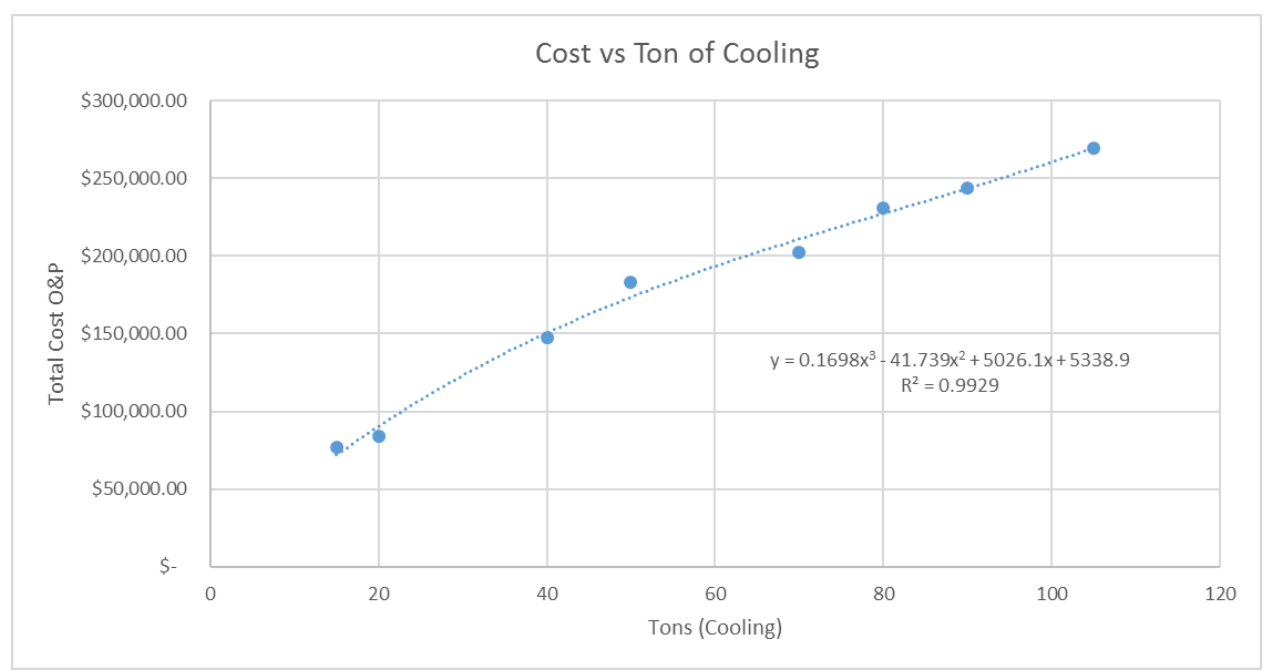

Fig. 14. Polynomial curve fit of available cost data of packaged VAV systems. 


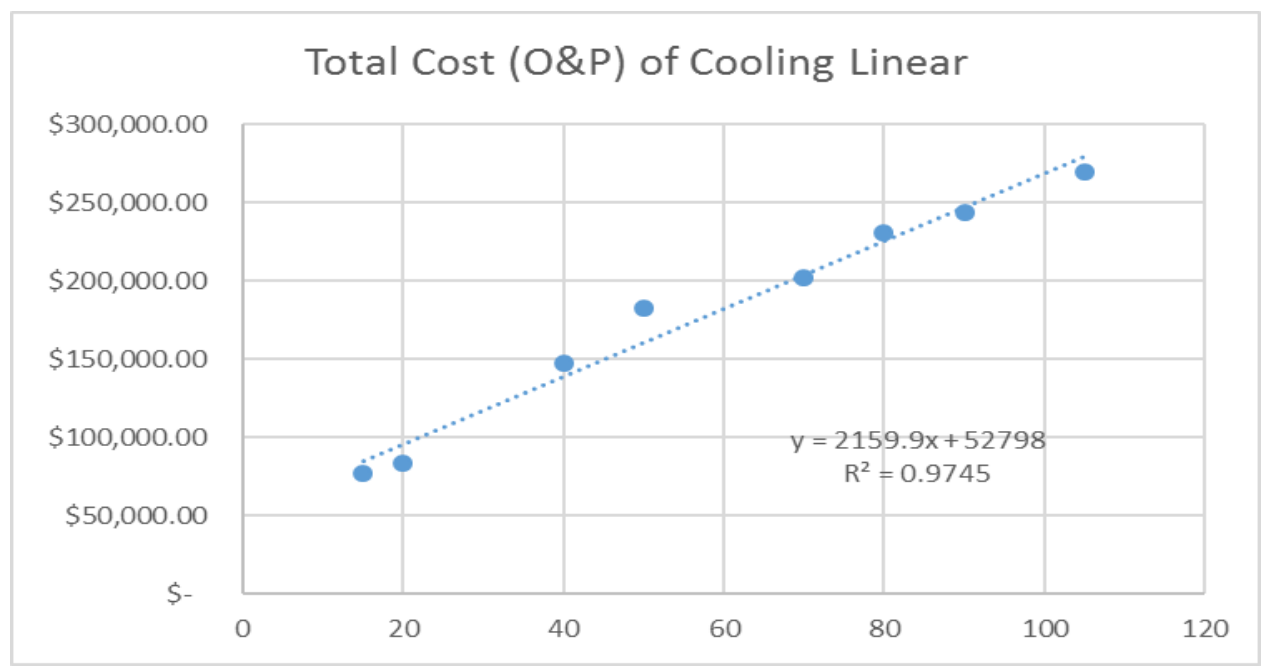

Fig. 15. Linear curve fit of available cost data of packaged VAV systems.

For large buildings like the secondary school, boilers and chillers are used to produce chilled and hot water, which is supplied to an air-handling unit (AHU) through a hydronic piping system. The AHU conditions and supplies cold or warm air to the building through a multi-zone ductwork. The installed costs of these HVAC equipment were obtained from RSMeans and listed in Tables 7 (for AHU), 8 (for water-cooled electric chiller), and 9 (for gas-fired hot water boiler).

\subsubsection{Ductwork}

According to RSMeans, the cost of a multi-zone ductwork is $\$ 2,802$ per cooling ton, which includes all the material, labor, overhead and profit for the ductwork installation.

\subsubsection{Water Distribution System}

RSMeans has data for hydronic piping installation cost, which is based on the material, diameter, length, and insulation level of the pipe. It also has cost data for circulation pump based on the size of the pump. However, a hydronic piping system design for the modeled buildings is necessary to estimate the cost of the water distribution system.

Table 7. Cost of Air-Handling Unit by Airflow Rate

\begin{tabular}{cccccc}
\hline CFM & Unit & Material & Labor & $\begin{array}{c}\text { Total } \\
\text { (bare) }\end{array}$ & $\begin{array}{c}\text { Total } \\
(\mathbf{O \& P})\end{array}$ \\
\hline $\mathbf{1 , 6 0 0}$ & Each & $\$ 5,100$ & $\$ 730$ & $\$ 5,830$ & $\$ 6,700$ \\
$\mathbf{5 , 0 0 0}$ & Each & $\$ 14,300$ & $\$ 970$ & $\$ 15,270$ & $\$ 17,175$ \\
$\mathbf{1 1 , 5 0 0}$ & Each & $\$ 25,500$ & $\$ 1,350$ & $\$ 26,850$ & $\$ 30,150$ \\
$\mathbf{2 2 , 0 0 0}$ & Each & $\$ 50,000$ & $\$ 2,275$ & $\$ 52,275$ & $\$ 58,425$ \\
$\mathbf{4 0 , 0 0 0}$ & Each & $\$ 92,000$ & $\$ 4,525$ & $\$ 96,525$ & $\$ 107,850$ \\
\hline
\end{tabular}


Table 8. Cost of Water-Cooled Electric Chiller by Capacity

\begin{tabular}{cccccc}
\hline $\begin{array}{c}\text { Capacity } \\
\text { (ton) }\end{array}$ & Unit & Material & Labor & $\begin{array}{c}\text { Total } \\
\text { (bare) }\end{array}$ & $\begin{array}{c}\text { Total } \\
(\text { O\&P) }\end{array}$ \\
\hline $\mathbf{1 0 0}$ & Each & $\$ 136,000$ & $\$ 14,200$ & $\$ 150,200$ & $\$ 171,000$ \\
$\mathbf{2 0 0}$ & Each & $\$ 183,000$ & $\$ 16,400$ & $\$ 199,400$ & $\$ 226,200$ \\
$\mathbf{3 0 0}$ & Each & $\$ 219,500$ & $\$ 17,300$ & $\$ 236,800$ & $\$ 267,600$ \\
\hline
\end{tabular}

Table 9. Cost of Gas-Fired Hot Water Boiler by Capacity

\begin{tabular}{cccccc}
\hline $\begin{array}{c}\text { Capacity } \\
(\mathbf{k B t u} / \mathbf{h r})\end{array}$ & Unit & Material & Labor & $\begin{array}{c}\text { Total } \\
(\text { bare })\end{array}$ & $\begin{array}{c}\text { Total } \\
(\mathbf{O \&})\end{array}$ \\
\hline $\mathbf{8 0}$ & Each & $\$ 1,975$ & $\$ 1,275$ & $\$ 3,250$ & $\$ 4,075$ \\
$\mathbf{3 2 0}$ & Each & $\$ 4,675$ & $\$ 2,300$ & $\$ 6,975$ & $\$ 8,650$ \\
$\mathbf{1 , 0 8 8}$ & Each & $\$ 13,500$ & $\$ 4,625$ & $\$ 18,125$ & $\$ 21,875$ \\
$\mathbf{2 , 8 5 6}$ & Each & $\$ 30,800$ & $\$ 9,250$ & $\$ 40,050$ & $\$ 47,900$ \\
$\mathbf{3 , 2 6 4}$ & Each & $\$ 32,700$ & $\$ 10,400$ & $\$ 43,100$ & $\$ 51,700$ \\
$\mathbf{6 , 1 0 0}$ & Each & $\$ 116,500$ & $\$ 14,400$ & $\$ 130,900$ & $\$ 150,300$ \\
$\mathbf{6 , 9 7 0}$ & Each & $\$ 131,500$ & $\$ 20,800$ & $\$ 152,300$ & $\$ 175,900$ \\
\hline
\end{tabular}

\section{UPDATED TECHNICAL POTENTIAL FOR RESIDENTIAL GHP APPLICATIONS}

After an update, the previous assessment of the technical potential of residential GHP applications (Liu 2010) now accounts for the entire residential sector rather than just the single-family homes, as well as the up-to-date efficiency of existing space heating (SH), space cooling (SC), and water heating (WH) equipment.

Table 10 summarizes the existing $\mathrm{SH}-\mathrm{SC}-\mathrm{WH}$ systems used in residential buildings and their energy efficiencies in 2000 and 2012 (EIA 2000 and EIA 2016). These data show that, though the energy efficiencies of existing conventional residential SH and WH equipment in 2012 are about the same as they were in 2000, the average energy efficiencies of existing residential SC equipment in 2012 are about $30 \%$ higher than a decade earlier.

In addition, Table 11 summarizes the calculated technical potential of residential GHPs, including primary energy savings, carbon emissions reductions, electricity peak demand reductions, and consumer energy cost savings throughout each census region and the nation as a whole. The percentages of primary energy savings of residential GHPs are significant, varying from $35.3 \%$ in the West to $46.5 \%$ in the South. Similar reduction percentages exist for $\mathrm{CO}_{2}$ emissions, peak electricity demand, and energy cost. The Southern census region has the greatest technical potential because its population, cooling demand, and usage of electric resistance water heating is the highest among all the census regions. 
Table 10. Typical SH-SC-WH systems Used in US Single-Family Units

\begin{tabular}{llcc}
\hline Energy services & Existing systems and equipment & $\begin{array}{c}\text { Rated efficiencies } \\
(\mathbf{2 0 0 0})\end{array}$ & $\begin{array}{c}\text { Rated efficiencies } \\
(\mathbf{2 0 1 2})\end{array}$ \\
\hline \multirow{5}{*}{ Space heating } & ASHP & $3.2 \mathrm{COP}$ & $3.2 \mathrm{COP}$ \\
& Electric heater & $1.00 \mathrm{EF}$ & $1.00 \mathrm{EF}$ \\
& Natural-gas-fired furnace/boiler & $0.8 \mathrm{AFUE}$ & $0.84 \mathrm{AFUE}$ \\
& Propane- or LPG-fired furnace/boiler & $0.80 \mathrm{AFUE}$ & $0.80 \mathrm{AFUE}$ \\
& Heating oil-fired furnace/boiler & $0.8 \mathrm{AFUE}$ & $0.86 \mathrm{AFUE}$ \\
\multirow{5}{*}{ Space cooling } & $10 \mathrm{SEER}$ & $13.2 \mathrm{SEER}$ \\
& CAC/ASHP & $7.7 \mathrm{SEER}$ & $9.9 \mathrm{SEER}$ \\
& RAC & $7.7-10 \mathrm{SEER}$ & $9.9-13.2 \mathrm{SEER}$ \\
& Combination of CAC and RAC & $0.88 \mathrm{EF}$ & $0.90 \mathrm{EF}$ \\
& Electric heater & $0.58 \mathrm{EF}$ & $0.61 \mathrm{EF}$ \\
& Natural gas heater & $0.58 \mathrm{EF}$ & $0.65 \mathrm{EF}$ \\
& Propane or LPG heater & $0.58 \mathrm{EF}$ & $0.58 \mathrm{EF}$ \\
\hline
\end{tabular}

Notes: AFUE, annual fuel utilization efficiency, is the ratio of the annual amount of heat actually delivered to the amount of fuel supplied to the furnace. COP, coefficient of performance, is the ratio of heating energy provided to the space to the electric energy consumed. The COP of the ASHP listed in the above table is measured at standard, mild weather $\left(47^{\circ} \mathrm{F}\right)$ rating conditions. EF , energy factor, indicates a water heater's overall energy efficiency based on the amount of hot water produced per unit of fuel consumed over a typical day. SEER, seasonal energy efficiency ratio, is the average annual cooling efficiency of an air-conditioning or heat pump system determined with a standard methodology and assuming typical weather. CAC stands for central air-conditioner, and RAC stands for room air-conditioner.

Table 11. Technical Potential of Residential GHPs

\begin{tabular}{lccccc}
\hline \multirow{2}{*}{ Benefits } & \multicolumn{5}{c}{ Technical Potential } \\
\cline { 2 - 6 } & Northeast & Midwest & South & West & Nation \\
\hline Annual primary energy savings (Quad BTU) & 0.9 & 1.2 & 1.9 & 0.6 & $\mathbf{4 . 6}$ \\
Percentage savings & $42.9 \%$ & $39.7 \%$ & $46.5 \%$ & $35.3 \%$ & $\mathbf{4 2 . 2 \%}$ \\
Annual $\mathrm{CO}_{2}$ emissions reduction (million & 62.7 & 72.4 & 125.0 & 36.5 & $\mathbf{2 9 6 . 6}$ \\
metric tons) & & & & & \\
Percentage savings & $44.2 \%$ & $39.1 \%$ & $46.6 \%$ & $35.1 \%$ & $\mathbf{4 2 . 4 \%}$ \\
Summer peak electrical demand reduction & 28.9 & 46.3 & 56.1 & 12.7 & $\mathbf{1 4 4 . 0}$ \\
(GW) & & & & & \\
Percentage savings & $53.8 \%$ & $47.1 \%$ & $36.8 \%$ & $50.4 \%$ & $\mathbf{4 2 . 2 \%}$ \\
Annual energy expenditures savings (billion \$) & 15.5 & 13.8 & 22.2 & 0.4 & $\mathbf{5 7 . 8}$ \\
Percentage savings & $47.2 \%$ & $45.1 \%$ & $48.3 \%$ & $37.2 \%$ & $\mathbf{4 5 . 7 \%}$ \\
\hline
\end{tabular}




\section{REFERENCES}

ASHRAE. 2004. Energy Standard for Buildings Except Low-Rise Residential Buildings. ANSI/ ASHRAE/IESNA Standard 90.1-2004. Atlanta, GA: American Society of Heating, Refrigerating and AirConditioning Engineers.

Battocletti, E. and W. Glassley. 2013. Measuring the Cost and Benefits of National Geothermal Heat Pump Deployment. Bob Lawrence \& Associates, Inc.

Eskilson, P. 1987. Thermal analysis of heat extraction boreholes. Doctoral thesis, University of Lund, Dept. of Mathematics, Lund, Sweden.

Liu, X., and G. Hellstrom. 2006. "Enhancements of an Integrated Simulation Tool for Ground-Source Heat Pump System Design and Energy Analysis," Proceedings of the 10th International Conference on Thermal Energy Storage, Richard Stockton College of New Jersey, May 31-June 2, 2006.

Liu, X. 2008. "Enhanced Design and Energy Analysis Tool for Geothermal Water Loop Heat Pump Systems," Proceedings of the 9th IEA Heat Pump Conference, May 20-22, 2008, Zurich, Switzerland.

Liu, X. (2010). Assessment of National Benefits from Retrofitting Existing Single-family Homes with Ground Source Heat Pump Systems, ORNL/TM-2010/122, Oak Ridge National Laboratory, Oak Ridge, TN. http://www.ornl.gov/sci/ees/etsd/btric/publications/Xiaobing/Liu_GHP_8-30-2010.pdf

NREL (National Renewable Energy Laboratory). 2007. Source Energy and Emission Factors for Energy Use in Buildings, Technical Report NREL/TP-550-38617, NREL, Washington, DC.

NREL (National Renewable Energy Laboratory). 2011. US Department of Energy Commercial Reference Building Models of the National Building Stock. NREL/TP-5500-46861.

RSMeans. 2016. Accessible online at https://www.rsmeans.com/products/online/building-constructioncost-data-online.aspx

US Energy Information Administration. 2000. Trends in Residential Air-Conditioning Usage from 1978 to 1997. http://www.eia.doe.gov/emeu/consumptionbriefs/recs/actrends/recs ac trends.html (accessed July 21, 2010).

US Energy Information Administration. 2016. (Table: Residential Sector Equipment Stock and Efficiency). http://www.eia.gov/beta/aeo/\#/?id=30-AEO2015\&region=00 \&cases $=$ ref 2015 highmacro $\sim$ highprice $\sim$ aeo 2014 full \&start $=2012 \&$ end $=2040 \& \mathrm{f}=$ A \& chartindexed $=0$

Wilcox, S and W. Marion. 2008. User Manual for TMY3 Data Sets. Technical Report NREL/TP-58143156, NREL, Washington, DC. 
